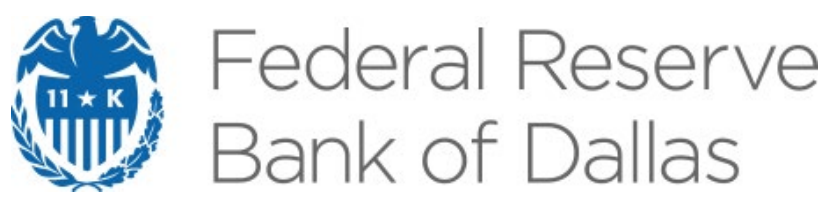

\title{
Rational Bubbles in Non-Linear Business Cycle Models: Closed and Open Economies
}

Robert Kollmann

\section{Globalization Institute Working Paper 378}

Research Department

https://doi.org/10.24149/gwp378

Working papers from the Federal Reserve Bank of Dallas are preliminary drafts circulated for professional comment. The views in this paper are those of the authors and do not necessarily reflect the views of the Federal Reserve Bank of Dallas or the Federal Reserve System. Any errors or omissions are the responsibility of the authors. 


\title{
Rational Bubbles in Non-Linear Business Cycle Models: Closed and Open Economies*
}

\author{
Robert Kollmann ${ }^{\dagger}$
}

January 29, 2020

\begin{abstract}
This paper studies rational bubbles in non-linear dynamic general equilibrium models of the macroeconomy. The term 'rational bubble' refers to multiple equilibria due to the absence of a transversality condition (TVC) for capital. The lack of TVC can be due to an OLG population structure. If a TVC is imposed, the macro models considered here have a unique solution. Bubbles reflect self-fulfilling fluctuations in agents' expectations about future investment. In contrast to explosive rational bubbles in linearized models (Blanchard (1979)), the rational bubbles in non-linear models here are bounded. Bounded rational bubbles provide a novel perspective on the drivers and mechanisms of business cycles. I construct bubbles (in non-linear models) that feature recurrent boom-bust cycles characterized by persistent investment and output expansions which are followed by abrupt contractions in real activity. Both closed and open economies are analyzed. In a non-linear two-country model with integrated financial markets, bubbles must be perfectly correlated across countries. Global bubbles may, thus, help to explain the synchronization of international business cycles.
\end{abstract}

JEL codes: E1, E3, F3, F4, C6

Keywords: rational bubbles, boom-bust cycles, business cycles in closed and open economies, non-linear DSGE models, Long-Plosser model, Dellas model

\footnotetext{
*I thank Sumru Altug and Julien Bengui for very insightful discussions. Thanks for useful comments are also due to Guido Ascari, Agustín Bénétrix, Florin Bilbie, Nuno Coimbra, Luca Dedola, Mick Devereux, Luca Fornaro, Jordi Gali, Tom Holden, Matthew Knowles, Michael Krause, Tommaso Monacelli, Gilles Saint-Paul, Cédric Tille, Gauthier Vermandel, Raf Wouters, and to workshop participants at National Bank of Belgium, St. Andrews University, University of Navarra, Swiss National Bank, Bundesbank, Paris School of Economics, Trinity College Dublin, Central Bank of Ireland, University of Cologne, and at IMFC, CEPR-MMCN, CEPR-IMF-ECB, JRC-European Commission, IMAC and DYNARE conferences. The views in this paper are those of the authors and do not necessarily reflect the views of the Federal Reserve Bank of Dallas or the Federal Reserve System.

${ }^{\dagger}$ Prof. R. Kollmann, Solvay Brussels School of Economics \& Management, Université Libre de Bruxelles, CP114, 50 Av. Roosevelt, 1050 Brussels, Belgium, robert kollmann@yahoo.com, www.robertkollmann.com.
} 


\section{Introduction}

This paper analyzes rational bubbles in non-linear dynamic stochastic general equilibrium (DSGE) models of the macroeconomy. Here, the notion of a 'rational bubble' refers to multiple equilibria due to the absence of a transversality condition (TVC) for capital. The lack of TVC can be justified by assuming an overlapping generations (OLG) population structure with finitely-lived households (see further discussion below). If a TVC is imposed, all models studied here have a unique solution. I consider models whose static equations and aggregate Euler equations are identical to those of standard Real Business Cycle (RBC) models. Agents have rational expectations. Rational bubbles in the models here reflect self-fulfilling fluctuations in agents' expectations about future investment.

A key finding is that rational bubbles in the non-linear macro models considered here are bounded. Bounded rational bubbles provide a novel perspective on the drivers and mechanisms of business cycle fluctuations. The boundedness of bubbles reflects non-linear effects. Bubbles in linearized versions of the models here are explosive, i.e. their expected trajectories tend to $\pm \infty$. Linearized versions of the present models have a unique stable solution.

I construct bubbles (in non-linear macro models) that feature recurrent boom-bust cycles characterized by persistent investment and output expansions which are followed by abrupt contractions in real activity. Numerical simulations show that bounded rational bubbles in nonlinear macro models can generate persistent fluctuations of real activity, and capture key business cycle stylized facts. Both closed and open economies are analyzed. A central finding for a nonlinear two-country model is that, with integrated financial markets, bounded bubbles must be perfectly correlated across countries. Global bubbles may, thus, help to explain the synchronization of international business cycles.

This paper builds on, and extends, Blanchard's (1979) pioneering work that first constructed explosive rational bubbles in simple linearized asset price models (see also Blanchard and Watson (1982)). Blanchard (1979) too assumes that there is no TVC. Blanchard's linearized models have a unique stable 'no-bubble' solution, like the linearized versions of the models studied here. Compared to Blanchard (1979), the main contribution of the present paper is to construct bounded recurrent bubbles in non-linear DSGE macro models without TVC.

The explosive bubbles generated by linearized models (Blanchard (1979)) are problematic. The accuracy of a linear model approximation can deteriorate sharply when the 
system deviates substantially from the point of approximation. In a macro model with decreasing returns to capital, explosive trajectories of capital and output are infeasible, as the capital stock cannot grow beyond a maximum level. A linearized model does not take this constraint into consideration, and it may also violate non-negativity constraints on consumption and output. By contrast, the present analysis of bubbles in non-linear models takes decreasing returns and boundary conditions into account. The non-linear model solutions presented here remain accurate when the economy deviates significantly from steady state (for several models discussed below, exact closed form solutions are provided).

Like Blanchard (1979), I assume a bubble process with two states: the economy can either be in a 'boom' state or in a 'bust' (crash) state. In a boom, capital investment and output diverge positively from the no-bubble decision rule that holds under the TVC (saddle path). High investment during a boom is sustained by the belief that, with positive probability, investment will continue to grow next period, which will depress future consumption and thereby raise the (expected) future marginal utility-weighted return of capital. In a bust, investment drops abruptly, and thereby reverts towards the no-bubble decision rule. Busts are triggered by selffulfilling downward revisions of expected future investment. Transitions between boom and busts are prompted by a random sunspot, and occur with an exogenous probability.

As pointed out above, I assume economies without transversality condition (TVC). Standard DSGE models postulate an optimizing infinitely-lived representative household. The set of optimality conditions of an infinitely-lived household's decision problem includes a TVC that stipulates that the value of capital has to be zero, at infinity. The TVC (in conjunction with static equilibrium conditions and Euler equations) defines a unique equilibrium, in standard DSGE models. I present a novel overlapping generations (OLG) structure with finitely-lived households that has the same static efficiency conditions and the same aggregate Euler equations as standard DSGE models. However, there is no TVC in that OLG structure. The key features of this OLG structure are: (i) complete risk sharing among contemporaneous generations; (ii) newborn agents receive a wealth endowment such that the consumption of newborns represents a time-invariant share of aggregate consumption. This OLG structure allows to generate rational bubbles in tractable non-linear DSGE models suitable for calibration to quarterly data. (Non-linear OLG business cycle models without the two key features mentioned 
above are typically much more cumbersome, due to the implied heterogeneity of generations, which makes stochastic analysis much more difficult.)

The results here are also relevant for research on numerical solution methods for DSGE models. Linearized DSGE models with a unique stable solution are the workhorses of modern quantitative macroeconomics (see, e.g., King and Rebelo (1999), Kollmann et al. (2011a,b) for overviews). This paper presents non-linear DSGE models (without TVC) that have multiple stable solutions, although the linearized versions of those models have a unique stable solution, as the number of eigenvalues (of the linearized state-space form) outside the unit circle equals the number of non-predetermined variables (Blanchard and Kahn (1980), Prop. 1). The classic Blanchard and Kahn (1980) condition for the existence and uniqueness of a stable solution for linear rational expectations models is, thus, irrelevant for non-linear models. Standard non-linear numerical solution methods for non-linear DSGE models (see overview in Judd (1998)) do not impose the TVC. Detecting TVC violations can be extremely difficult, in non-linear stochastic economies (as those violations can be caused by very low-probability events in a distant future). The results presented here suggest that the set of stable non-linear model solutions, without TVC, can be much larger than hitherto understood.

A large literature has studied linearized DSGE models with multiple stationary sunspot equilibria. These multiple equilibria arise if the number of eigenvalues (of the linearized statespace form) outside the unit circle is less than the number of non-predetermined variables (Blanchard and Kahn (1980), Prop. 3). ${ }^{1}$ Linearized models may exhibit stationary sunspot equilibria if increasing returns and/or externalities (e.g., Schmitt-Grohé (1997), Benhabib and Farmer (1999)), financial frictions (e.g., Martin and Ventura (2018)) or certain OLG population structures (e.g., Woodford (1986), Galí (2018)) are assumed. The specific features and calibrations that deliver stationary sunspot equilibria in linearized models can be debatable. ${ }^{2}$ By contrast, the paper here presents multiple equilibria in non-linear DSGE models--without the features that were just mentioned; as discussed above, the linearized versions of the models here have a unique stable solution.

\footnotetext{
${ }^{1}$ See Taylor (1977) for an early example of a model with sunspots, due to the presence of 'too many' stable roots.

${ }^{2}$ E.g., increasing returns/externalities need to be sufficiently strong; in OLG models the steady state interest rate has to be smaller than the trend growth rate $(\mathrm{r}<\mathrm{g})$ etc. Note that, in the novel OLG structure developed in the paper here $\mathrm{r}>\mathrm{g}$ holds. Linearized versions of the OLG structure here have a unique stable solution (as discussed above).
} 
The notion of a rational bubble introduced by Blanchard (1979) has been highly influential in the literature on asset prices (e.g., see Mussa (1990) and Stracca (2004) for references). ${ }^{3}$ However, so far, this notion has had little much less impact on structural macroeconomics.

Ascari et al. (2019) study temporarily explosive bubbles, in a standard linearized threeequation New Keynesian macro model (without capital accumulation). The authors assume bounded rationality, and postulate that, once an explosive path reaches a threshold, the economy reverts permanently to its unique saddle path. Under full rational expectations, the future switch to the saddle path would, from the outset, rule out the emergence of bubbles. ${ }^{4}$ By contrast, the present analysis considers stable (bounded) bubbles in non-linear models. Limited rationality is not needed to generate stable bubble equilibria, in the present framework. The paper here considers 'real' economies with capital, but the analysis abstracts from nominal rigidities and monetary policy. In ongoing work, I am exploring rational bounded bubbles in non-linear economies with Keynesian features.

Multiple equilibria due to non-linearities are also studied by Holden (2016a,b) who shows that multiple equilibria can exist when occasionally binding constraints, OBC (such as a zero-lower-bound constraint for the interest rate) are integrated into an otherwise linear DSGE model (the linear model has a unique stable solution when the $\mathrm{OBC}$ is ignored). By contrast, the analysis here considers fully non-linear models. The multiple equilibria described here have a 'bubbly' dynamics that differs from the dynamics studied by Holden (2016a,b). ${ }^{5}$

The bubble equilibria discussed in this paper imply that the distribution of endogenous variables is heteroscedastic: the conditional variance of forecast errors of future endogenous variables is greater, the longer a boom driven by self-fulfilling expectations has lasted. In this sense, the present paper is related to Bacchetta et al. (2012) who study a stylized asset pricing model in which bounded stock price bubbles can arise if the sunspot shock and the asset price are

\footnotetext{
${ }^{3}$ Google Scholar records 2615 cites (01/2020) for Blanchard (1979) and its companion paper Blanchard and Watson (1982).

${ }^{4}$ In their quantitative model, Ascari et al. (2019) set the threshold (that triggers reversion to the stable saddle path) at a very large value, so that switches to the stable saddle path occur in a distant future. The authors assume that those faraway future switches are disregarded by agents, in the model.

${ }^{5}$ Holden highlights indeterminacy of the length of time during which the $\mathrm{OBC}$ binds, and he focuses on fluctuations in the vicinity of the OBC.
} 
heteroscedastic. The work here highlights the importance of heteroscedasticity of real activity, for generating bounded bubble equilibria, in non-linear DSGE business cycle models.

The next Section discusses bounded rational bubbles that arise in the Long and Plosser (1983) RBC model, when the TVC is dropped. That model assumes a closed economy with log utility, a Cobb-Douglas production function and full capital depreciation. Exact closed form solutions with bubbles can be derived for that model. Section 3 considers a non-linear closed economy model with incomplete capital depreciation. Sections 4 and 5 study rational bubbles in non-linear two-country models.

\section{Rational bubbles in a Long-Plosser RBC economy without TVC}

Following Long and Plosser (1983), this Section considers a closed economy with timeseparable preferences. The period utility function is $u\left(C_{t}\right)=\ln \left(C_{t}\right)$, where $C_{t}$ denotes consumption in period $t$. The production function is:

$$
Y_{t}=\theta_{t} K_{t}^{\alpha}, 0<\alpha<1,
$$

where $Y_{t}, K_{t}, \theta_{t}>0$ are output, capital and exogenous total factor productivity (TFP). For simplicity, I assume that labor hours are constant and normalized to unity (the next Sections allow for variable hours). The resource constraint is

$$
C_{t}+I_{t}=Y_{t},
$$

where $I_{t}$ is (gross) investment. The capital depreciation rate is $100 \%$, so that investment equals next period's capital stock: $I_{t}=K_{t+1}$. The household's Euler equation is $E_{t} \beta\left\{U^{\prime}\left(C_{t+1}\right) / U^{\prime}\left(C_{t}\right)\right\} \partial Y_{t+1} / \partial K_{t+1}=1$, where $0<\beta<1$ is the subjective discount factor. Thus,

$$
E_{t} \beta\left(C_{t} / C_{t+1}\right) \alpha Y_{t+1} / K_{t+1}=1 .
$$

Substitution of the resource constraint into the Euler equation gives an expectational difference equation in the investment/output ratio $Z_{t} \equiv K_{t+1} / Y_{t}$ :

$$
E_{t} H\left(Z_{t+1}, Z_{t}\right)=1 \text {, with } H\left(Z_{t+1}, Z_{t}\right) \equiv \alpha \beta\left[\left(1-Z_{t}\right) /\left(1-Z_{t+1}\right)\right] / Z_{t} .
$$

Long and Plosser (1983) assume an infinitely-lived representative household. The necessary and sufficient optimality conditions of the infinitely-lived household's decision problem are the 
household's resource constraint and Euler equation (summarized by (4)) and a transversality condition (TVC) that requires that the value of the capital stock is zero, at infinity: $\lim _{\tau \rightarrow \infty} \beta^{\tau} E_{t} u^{\prime}\left(C_{t+\tau}\right) K_{t+\tau+1}=0$. Note that $u^{\prime}\left(C_{t}\right) K_{t+1}=K_{t+1} / C_{t}=Z_{t} /\left(1-Z_{t}\right)$. It can readily be seen that $Z_{t}=\alpha \beta \forall t$ satisfies (4) and the TVC. This solution corresponds to the textbook solution of the Long-Plosser model (e.g., Blanchard and Fischer (1989)). Under that solution, consumption and investment are time-invariant shares of output: $C_{t}=(1-\alpha \beta) Y_{t}, K_{t+1}=\alpha \beta Y_{t} \quad \forall t$.

In what follows, I postulate that there is no TVC. This gives rise to multiple equilibria. I refer to a process $\left\{Z_{t}\right\}$ that solves (4), but that differs from the textbook solution (derived under the TVC), as a rational bubble equilibrium, or (rational) bubble, for short. Thus, rational bubbles feature an investment/output ratio that differs from $\alpha \beta$, in at least one period. Bubbles violate the TVC. ${ }^{6}$

Throughout this paper, the term 'rational bubble' refers to (multiple) equilibria, due to the absence of a transversality condition (TVC) for capital. If the TVC were imposed, all models studied in this paper would have a unique solution.

The lack of TVC can be justified by the assumption that the economy has an overlapping generations (OLG) population structure with finitely-lived agents. Appendix A presents a novel OLG structure with finitely-lived agents that has the same aggregate resource constraint and the same aggregate Euler equation as a Long-Plosser economy inhabited by an infinitely-lived representative agent. Thus equations (1)-(4) continue to hold in that OLG structure. However, the TVC does not hold in the OLG structure, due to agents' finite horizon. Two key features of this OLG structure are: (I) Complete risk sharing among contemporaneous generations. (II) Newborn agents receive a wealth endowment such that the consumption of newborns represents a timeinvariant share of aggregate consumption; under log utility, this requires that the wealth

\footnotetext{
${ }^{6}$ The decision problem of the infinitely-lived representative household assumed by Long and Plosser has a unique solution, as that decision problem is a well-behaved concave programming problem. Thus, $Z_{t}=\alpha \beta \forall t$ is the only solution that satisfies (4) and the TVC. Hence, any bubble process $Z_{t} \neq \alpha \beta$ satisfying (4) violates the TVC. Under the bubble process (9) discussed below, $Z_{t}$ approaches 1 if a long uninterrupted string of 'boom' sunspots is realized, which entails large positive values of $Z_{t} /\left(1-Z_{t}\right)$. Although this only happens with a very small probability, it causes the TVC to be violated.
} 
endowments of newborns is a time-invariant fraction of aggregate wealth. ${ }^{7}$ Assumptions (I) and (II) allow to derive simple non-linear dynamic relations among aggregate variables that allow to easily solve for those aggregates. This OLG structure, thus, allows to generate rational bubble equilibria in tractable non-linear DSGE models suitable for calibration to quarterly data. (OLG business cycle models without the two key features mentioned above are typically much more cumbersome, due to the implied heterogeneity of generations, which makes non-linear stochastic analysis much more difficult. Without assumptions (I),(II), approximate aggregation across generations may still be possible, based on linearization. The focus of the paper here is on rational bubbles in non-linear models. Thus, aggregation based on linear approximations is not useful here.)

Besides assuming an OLG structure, another motivation for disregarding the TVC is that detecting TVC violations may be very difficult, in non-linear stochastic economies that are more complicated than the Long-Plosser economy, i.e. in models for which no closed form solution exists (see below). TVC violations can be caused by low-probability events in a distant future. Agents may thus lack the cognitive/computing power to detect deviations from the TVC (see discussion in Blanchard and Watson (1982)).

\subsection{Rational bubbles in the linearized model}

Linearization of (4) around $Z=\alpha \beta$ gives:

$$
E_{t} z_{t+1}=\lambda z_{t}, \text { with } z_{t} \equiv Z_{t}-Z \text { and } \lambda \equiv 1 /(\alpha \beta)>1 \text {. }
$$

$\lambda$, the eigenvalue of (5), exceeds unity. The model has one non-predetermined variable $\left(z_{t}\right)$. Therefore, the number of eigenvalues outside the unit circle equals the number of nonpredetermined variables. Hence, the linearized model has a unique non-explosive solution (Blanchard and Kahn (1980), Prop. 1). This solution is given by $z_{t}=0$, i.e. $Z_{t}=\alpha \beta \forall t$, which corresponds to the textbook solution of the Long-Plosser model (with TVC).

Blanchard (1979) pointed out that a linear expectational difference equation of form (5) is also solved by a bubble process $\left\{z_{t}\right\}$ such that

\footnotetext{
${ }^{7}$ The wealth endowment of newborn may be provided by bequests, or by a government transfer financed by taxes levied on older generations. In reality, all societies make significant transfers to young generations (e.g., through spending on their health and education). Wealthy countries make bigger transfers to the young than poor countries. It seems reasonable to assume that the wealth endowment of the young is a (roughly) constant share of total wealth.
} 


$$
z_{t+1}=[\lambda /(1-\pi)] \cdot z_{t} \text { with probability } 1-\pi \text { and } z_{t+1}=0 \text { with probability } \pi \quad(0<\pi<1) .
$$

If $z_{t} \neq 0$, then next period the system continues to diverge with probability $1-\pi$, while a 'bust' (return to the no-bubble solution) occurs with probability $\pi$. Process (6) implies that after a bust, non-zero values of $z$ never arise again, i.e. the bubble is 'self-ending'. Recurrent (neverending) bubbles obtain if a bust implies a value $\mu \neq 0: z_{t+1}=\left(\lambda z_{t}-\mu \pi\right) /(1-\pi)$ with probability $1-\pi$ and $z_{t+1}=\mu$ with probability $\pi$.

An important feature of rational bubbles in the linearized model (5) is that the expected path of the investment/output ratio explodes: $\lim _{s \rightarrow \infty} E_{t} z_{t+s}=\infty$ when $z_{t}>0$ and $\lim _{s \rightarrow \infty} E_{t} z_{t+s}=-\infty$ when $z_{t}<0$. This explosiveness greatly limits the appeal of rational bubbles in the linearized model. Note that the investment/ output ratio $Z_{t}$ is bounded by 0 and 1: an infinite investment ratio is not feasible. The linear approximation (on which (5) is based) neglects this constraint. A linear approximation is thus not suitable for studying rational bubbles.

\subsection{Rational bubbles in the non-linear model}

By contrast to the linearized model, the non-linear model can produce bounded bubbles. Note that the non-linear model (4) holds for any process $\left\{Z_{t}\right\}$ such that

$$
\alpha \beta\left[\left(1-Z_{t}\right) /\left(1-Z_{t+1}\right)\right] / Z_{t}=1+\varepsilon_{t+1},
$$

where $\varepsilon_{t+1}$ is an Euler equation forecast error with zero conditional mean: $E_{t} \varepsilon_{t+1}=0 . \quad \varepsilon_{t+1}$ reflects unanticipated changes in $Z_{t+1}$ that are driven by changes in households' expectations about the future path $\left\{Z_{t+s}\right\}_{s>1}$. (7) can be written as:

$$
Z_{t+1}=\Lambda\left(Z_{t}, \varepsilon_{t+1}\right) \equiv 1-\alpha \beta\left(1 / Z_{t}-1\right) /\left(1+\varepsilon_{t+1}\right) .
$$

$Z_{t+1}$ is strictly increasing and strictly concave in both $Z_{t}$ and in $\varepsilon_{t+1}$, for $\varepsilon_{t+1}>-1$. The strict concavity reflects decreasing returns and the convexity of the marginal utility of consumption (prudence). Figure1 plots $Z_{t+1}$ as a function of $Z_{t}$, and that for three values of the Euler equation forecast error $\varepsilon_{t+1}: \varepsilon_{t+1}=0$ (thick black line), $\varepsilon_{t+1}=0.5$ and $\varepsilon_{t+1}=-0.5$ (thin dashed 
lines). Throughout this paper, I set $\alpha=1 / 3$ and $\beta=0.99$, so that $\alpha \beta=0.33$. These parameter values are standard in quarterly business cycle models.

\subsubsection{Deterministic economy}

Consider first a deterministic economy, in which $\varepsilon_{t+1}=0$ holds $\forall t$, so that the investment/output ratio obeys $Z_{t+1}=\Lambda\left(Z_{t}, 0\right)$ (see curve labelled ' $\varepsilon_{t+1}=0$ ' in Fig. 1). The graph of $Z_{t+1}=\Lambda\left(Z_{t}, 0\right)$ shows combinations of $Z_{t}$ and $Z_{t+1}$ that are consistent (in a deterministic economy) with the date $t$ Euler equation and with the resource constraints at $t$ and $t+1$. A rise in $Z_{t}$ increases investment and lowers consumption at date $t$, which raises the marginal utility of consumption at $t$; output at $t+1$ rises too, while the marginal product of capital at $t+1$ falls. The household's Euler equation thus requires that marginal utility of consumption at $t+1$ has to increase, which calls for a fall in consumption at $t+1$. Thus, a rise in $Z_{t}$ has to be followed by a fall in the consumption/output ratio at $t+1$, and hence by an increase in $Z_{t+1}$ (the investment/output ratio at $t+1$ ). This explains the positive relation between $Z_{t}$ and $Z_{t+1}$.

As illustrated in Fig. 1, the function $Z_{t+1}=\Lambda\left(Z_{t}, 0\right)$ cuts the 45 -degree line at two points: $\mathrm{Z}=\alpha \beta$ and $\mathrm{Z}=1$. The slope of the mapping from $Z_{t}$ to $Z_{t+1}$ is $1 /(\alpha \beta)>1$, at the no-bubble solution $\mathrm{Z}=\alpha \beta$. In a deterministic economy, a realization $\mathrm{Z}_{t} \neq \alpha \beta$ puts the investment ratio on a monotone trajectory that reaches $Z=0$ in finite time, or that asymptotes to $Z=1$ (without ever reaching $Z=1)$.

\subsubsection{Stochastic bubbles}

I now show that the Long-Plosser economy without TVC has stochastic bubble equilibria that feature recurrent, bounded fluctuations. These equilibria do not converge to $Z=0$ or $Z=1$. Trajectories that lead to $Z=0$ (zero capital and output: economic 'extinction'), or that converge to $Z=1$ (zero consumption share) seem empirically irrelevant. Standard DSGE macro analysis focuses on stationary fluctuations in economic activity driven by exogenous stationary shocks to TFP (and other fundamentals). Therefore, this paper concentrates on recurrent bubbles, i.e. bubbles that are not self-ending and that do not lead to economic extinction. 
When $Z_{t}<\alpha \beta$, then the law of motion (8) implies that the economy can hit a zero-capital corner solution in subsequent periods (see Figure 1). Once the zero-capital corner is reached, output, investment and consumption remain at zero forever. Thus, a recurrent stochastic bubble must feature an investment/output ratio that always stays in the interval $[\alpha \beta, 1)$. The bubble equilibria studied here thus exhibit capital over-accumulation (the investment/output ratio being at least as large as in the textbook no-bubble equilibrium that holds under the TVC). In contrast, (explosive) rational bubbles in the linearized model can be positive or negative.

By analogy to the Blanchard (1979) bubble, I assume that there are two possible states at $t+1$, with a negative and a positive realization of the Euler equation forecast error $\varepsilon_{t+1}$, respectively. These two states indicate a 'bust' and a 'boom' at $t+1$. Let $\varepsilon_{t+1}$ take these values: $-\overline{\varepsilon_{t}}$ and $\overline{\varepsilon_{t}} \cdot \pi /(1-\pi)$ with exogenous probabilities $\pi$ and $1-\pi$, respectively, where $\overline{\varepsilon_{t}} \in[0,1)$ and $0<\pi<1 . Z_{t+1}$ then takes these two values with probabilities $\pi$ and $1-\pi$ :

$$
Z_{t+1}^{L} \equiv \Lambda\left(Z_{t},-\overline{\varepsilon_{t}}\right) \text { and } Z_{t+1}^{H} \equiv \Lambda\left(Z_{t}, \overline{\varepsilon_{t}} \pi /(1-\pi)\right) \text { with } Z_{t+1}^{L} \leq Z_{t+1}^{H} \leq 1 \text {. }
$$

\section{Recurrent rational bubbles}

In the spirit of the recurrent Blanchard (1979) bubbles in the linearized model (see discussion above), I assume that when an investment bust occurs in period $t+1$, then agents choose an investment/output ratio that is close to the no-bubble investment/output ratio $\alpha \beta$. Throughout the rest of this Section, I set $Z_{t+1}^{L}=\alpha \beta+\Delta$, where $\Delta>0$ is a small positive constant. A strictly positive $\Delta$ is needed to generate recurrent bubbles. $\Delta=0$ would imply that bubbles are selfending, while $\Delta<0$ would entail that the economy will ultimately hit the zero-capital corner (as discussed above). ${ }^{8}$

When $Z_{t+1}^{L}=\alpha \beta+\Delta$ is assumed, the first equation shown in (9) pins down $-\overline{\varepsilon_{t}}$ as a function of $Z_{t}$; substitution into the second equation in (9) then determines $Z_{t+1}^{H}$. Let $Z_{t+1}^{H}=\Psi\left(Z_{t}\right)$

\footnotetext{
${ }^{8}$ Assume $\Delta=0$ (so that $Z_{t+1}^{L}=\alpha \beta$ ) and consider what happens when $Z_{t}=\alpha \beta$. The first equation shown in (9) then becomes $\alpha \beta \equiv \Lambda\left(\alpha \beta,-\overline{\varepsilon_{t}}\right)$ which implies $\overline{\varepsilon_{t}}=0$, so that $Z_{t+1}^{H}=Z_{t+1}^{L}=\alpha \beta$, i.e. $Z$ is stuck at $\alpha \beta$ in all subsequent periods. Setting $\Delta>0$ rules out that absorbing state
} 
denote the (unique) value of $Z_{t+1}^{H}$ that is associated with $Z_{t}$ (given $Z_{t+1}^{L}=\alpha \beta+\Delta$, and given the bust probability $\pi$ ).

Note that under the assumed bubble process (with $Z_{t+1}^{L}=\alpha \beta+\Delta$ ), the date $t$ Euler equation (4) can be expressed as

$$
\pi H\left(\alpha \beta+\Delta, Z_{t}\right)+(1-\pi) H\left(Z_{t+1}^{H}, Z_{t}\right)=1
$$

$Z_{t+1}^{H}=\Psi\left(Z_{t}\right)$ solves this equation. It can be verified that, for $Z_{t} \in[\alpha \beta+\Delta, 1]$, the function $\Psi$ has these properties: (i) $\Psi^{\prime}>0, \Psi^{\prime \prime}<0$; (ii) $Z_{t}<\Psi\left(Z_{t}\right) \leq 1$.

Thus, $Z_{t+1}^{H}$ is a strictly increasing and strictly concave function of $Z_{t}$. Furthermore, $Z_{t+1}^{H}$ exceeds $Z_{t}$; if a boom occurs at $t+1$, then the investment/output ratio in that periods exceeds the investment/output ratio at $t$. Therefore, $Z_{t} \in[\alpha \beta+\Delta, 1)$ implies that $Z_{\tau} \in[\alpha \beta+\Delta, 1)$ holds $\forall \tau>t$. (It can also be shown that $\Lambda\left(Z_{t}, 0\right)<\Psi\left(Z_{t}\right)$, so that $Z_{t+1}^{H}$ exceeds the value that would obtain in a deterministic economy, given $Z_{t}$.)

Consider an economy that starts in period $t=0$, with an exogenous initial capital stock $K_{0}$. Let $u_{t} \in\{0 ; 1\}$ be an exogenous i.i.d. sunspot that takes values 0 and 1 with probabilities $\pi$ and $1-\pi$, respectively, where $0<\pi<1$. Then the following process for the investment/output ratio $\left\{Z_{t}\right\}_{t \geq 0}$ is a recurrent rational bubble: $Z_{0} \in[\alpha \beta+\Delta, 1)$ and $Z_{t+1}=Z_{t+1}^{L} \equiv \alpha \beta+\Delta$ if $u_{t+1}=0$ and $Z_{t+1}=Z_{t+1}^{H}$ if $u_{t+1}=1$, for $t \geq 0$, where $Z_{t+1}^{H}=\Psi\left(Z_{t}\right)$ solves the date $t$ Euler equation (10).

Note that the investment/output ratio in the initial period, $Z_{0}$, does not obey the recursion that governs the investment ratio in subsequent periods. Thus, $Z_{0}$ is indeterminate. However, $Z_{0} \in[\alpha \beta+\Delta, 1)$ has to hold to ensure that investment/output ratios in all subsequent periods lie in the interval $[\alpha \beta+\Delta, 1)$. Given a sequence $\left\{Z_{t}\right\}_{t \geq 0}$, the path of capital $\left\{K_{t+1}\right\}_{t \geq 0}$ can be generated recursively (for the given initial capital stock $K_{0}$ ) using $K_{t+1}=Z_{t+1} \theta_{t}\left(K_{t}\right)^{\alpha}$ for $\mathrm{t} \geq 0 .{ }^{9}$

\footnotetext{
${ }^{9}$ In the stochastic simulations discussed below, the initial investment/output ratio is set at $Z_{0}=\alpha \beta+\Delta$. The effect of the initial $Z_{0}$ on subsequent simulated values vanishes fast. $Z_{0}$ does not noticeably affect simulated moments over a long simulation run.
} 
In a deterministic economy, the investment-output ratio would rise steadily and converge to unity, after a value $\mathrm{Z}_{t}>\alpha \beta$ is realized. In a stochastic bubble equilibrium, an uninterrupted infinite sequence of investment booms $(u=1)$ would asymptotically drive the investment/output ratio to unity. Of course, an uninterrupted boom run has zero probability. At any time, the investment output ratio can drop to $\alpha \beta+\Delta$, with probability $\pi$. This ensures that the investment/output ratio undergoes recurrent fluctuations. Bubbles induce fluctuations of real activity that remain most of the time near the steady state of a no-bubble economy, if the bust probability $\pi$ is sufficiently big and if $\Delta>0$ is sufficiently close to zero. In the stochastic simulations reported below, the unconditional mean of endogenous variables is close to the nobubble steady state.

What expectations sustain the rational bubble equilibrium? Agents expect at date $t$ that $Z_{t+1}$ will equal $Z_{t+1}^{L}=\alpha \beta+\Delta$ or $Z_{t+1}^{H}=\Psi\left(Z_{t}\right)$ with probabilities $\pi$ and 1- $\pi$, respectively, where the values of $Z_{t+1}^{L}$ and $Z_{t+1}^{H}$ are known at $t$. At date $t+1$, agents are free to choose a value of $Z_{t+1}$ that differs from $Z_{t+1}^{L}$ or $Z_{t+1}^{H}$; however, in a bubble equilibrium, they chose not to do so because a choice $Z_{t+1} \in\left\{Z_{t+1}^{L}, Z_{t+1}^{H}\right\}$ is 'validated' by their date $t+1$ expectations about $Z_{t+2}$. Assume that a bust occurs in $t+1 \quad\left(u_{t+1}=0\right)$, so that agents choose $Z_{t+1}=\alpha \beta+\Delta$; in equilibrium, this choice is sustained by agents' expectation (at $t+1$ ) that $Z_{t+2}$ will equal $\alpha \beta+\Delta$ or $\Psi(\alpha \beta+\Delta)$ with probabilities $\pi$ and $1-\pi$, respectively. By contrast, if a boom occurs at $t+1\left(u_{t+1}=1\right)$, agents choose $Z_{t+1}=Z_{t+1}^{H}=\Psi\left(Z_{t}\right)$; this choice is supported by the expectation (at $\mathrm{t}+1$ ) that $Z_{t+2}$ will equal $\alpha \beta+\Delta$ or $\Psi\left(Z_{t+1}^{H}\right)=\Psi\left(\Psi\left(Z_{t}\right)\right)$ with probabilities $\pi$ and $1-\pi$, respectively. Note that $\Psi(\alpha \beta+\Delta)<\Psi\left(\Psi\left(Z_{t}\right)\right)$. This shows that, in a boom (at date $\mathrm{t}+1$ ), agents are more optimistic about $Z_{t+2}$ than in a bust (at $\left.\mathrm{t}+1\right)$.

As in Blanchard (1979), booms and busts reflect hence self-fulfilling variations in agents' expectations about the future state of the economy. An investment boom [bust] is triggered by a more [less] optimistic assessment of next period's investment/output ratio. 


\subsubsection{Quantitative results: bubble equilibrium}

I next discuss numerical simulations of a bubble equilibrium. In order to assess whether a rational bubble alone can generate a realistic business cycle, I assume that TFP is constant. The bust probability is set $\pi=0.5$. I set $\Delta=10^{-6}$, as that value produces standard deviations of real activity (HP filtered) in the empirical range. As indicated previously, $\alpha=1 / 3$ and $\beta=0.99$ are assumed in all simulations.

Panel (1) of Fig. 2 plots $Z_{t+1}^{L}=\alpha \beta+\Delta, \quad Z_{t+1}^{H}=\Psi\left(Z_{t}\right)$ and the conditional mean $E_{t} Z_{t+1}=\pi_{t} Z_{t+1}^{L}+\left(1-\pi_{t}\right) Z_{t+1}^{H}$, as functions of $Z_{t}$. Also shown in Panel (1) is the value of $Z_{t+1}$ that would obtain in a deterministic economy $\left(\varepsilon_{t+1}=0\right): Z_{t+1}=\Lambda\left(Z_{t}, 0\right)$. In the stochastic bubble equilibrium, the investment/output ratio grows between $t$ and $t+1 \quad\left(Z_{t+1}>Z_{t}\right)$ when a boom occurs at $t+1 \quad\left(u_{t+1}=1\right)$; when there is a bust at $t+1 \quad\left(u_{t+1}=0\right)$, the investment rate either remains unchanged at $\alpha \beta+\Delta$ (if $Z_{t}=\alpha \beta+\Delta$ ), or it drops to $Z_{t+1}=\alpha \beta+\Delta$ (if $Z_{t}>\alpha \beta+\Delta$ ).

Fig. 2 shows that $Z_{t+1}^{H}=\Psi\left(Z_{t}\right)$ is a steeply increasing function of $Z_{t}$. In a bubble equilibrium, a sequence of booms $(u=1)$ generates, thus, a run of rapid increases in the investment/output ratio; this is followed by an abrupt contraction once a bust $(u=0)$ occurs. A sequence of busts keeps the investment ratio at the lower bound $\alpha \beta+\Delta .{ }^{10}$

The strict concavity of the recursion $Z_{t+1}=\Lambda\left(Z_{t}, \varepsilon_{t+1}\right)$ with respect to the Euler equation forecast error $\varepsilon_{t+1}$ (see (8)) implies that $E_{t} Z_{t+1}<\Lambda\left(Z_{t}, 0\right)$; thus, the conditional mean of the date $\mathrm{t}+1$ investment ratio $E_{t} Z_{t+1}$ is strictly below the value of $Z_{t+1}$ that would obtain in a deterministic economy $\left(\Lambda\left(Z_{t}, 0\right)\right)$. The unconditional mean of the investment ratio is $E(Z)=0.3333$ which is very close to (but greater than) $\alpha \beta+\Delta .^{11}$

\footnotetext{
${ }^{10}$ Note that the variance of the forecast error $\varepsilon_{t+1}$ is an increasing function of $Z_{t}$, i.e. $\varepsilon_{t+1}$ is heteroscedastic. The conditional variance of $Z_{t+1}$ is likewise increasing in $Z_{t}$.

$11 E_{t} Z_{t+1}$ is an increasing and strictly concave function of $Z_{t}: E_{t} Z_{t+1}=\zeta\left(Z_{t}\right), \quad \zeta^{\prime}>0, \zeta^{\prime \prime}<0$. The graph of $E_{t} Z_{t+1}$ intersects the 45 -degree line at $Z_{t}=0.599$. The unconditional mean $E(Z)$ is (much) smaller than that point of intersection, due to the strict concavity of $\zeta \quad(E(Z)=E(\zeta(Z))<\zeta(E(Z)))$.
} 


\section{Business cycle statistics}

Panel (2) of Fig. 2 shows representative simulated paths of output (Y, continuous black line), consumption ( $\mathrm{C}$, red dashed line) and investment (I, blue dash-dotted line). The Figure shows that the bubble model generates sudden, but short-lived, expansions in output and investment. During the expansion phase of a bubble, the rapid rise in investment is accompanied by a contraction in consumption.

Table 1 (Row (a)) reports model-generated standard deviations (in \%) and crosscorrelations of HP filtered logged time series of output $(Y)$, consumption $(C)$ and investment $(I)$; also shown are mean values of these variables and of the investment/output ratio ( $Z$ ). All modelgenerated business cycle statistics reported in Table 1 (and in subsequent Tables) are based on one simulation run of $\mathrm{T}=10000$ periods. The reported theoretical business cycle statistics are median statistics computed across rolling windows of 200 periods. ${ }^{12}$ Mean values (of $Y, C, I$ and $Z$ ) are computed using the whole simulation run (T periods) and expressed as $\%$ deviations of the deterministic steady state (of the no-bubble economy).

To evaluate the model predictions, Table 1 also reports US historical business statistics based on HP filtered quarterly data for the period 1968q1-2017q4 (see Row (b)). The empirical standard deviations of GDP, consumption and investment are 1.47\%, 1.19\% and 4.96\%, respectively. In the data, consumption and investment are strongly procyclical; these variables and GDP are highly serially correlated.

The model-predicted standard deviations of output, consumption and investment are 1.14\%, 2.35\% and 3.41\%, respectively (see Row (a) of Table 1). Thus, the model underpredicts slightly the empirical volatility of output and investment; however, consumption is more volatile in the model than in the data. In the model, consumption and investment are procyclical; output and investment are predicted to be positively serially correlated, while consumption is predicted to be negatively autocorrelated. In the bubble economy, average output and investment are $0.5 \%$ and $2.3 \%$ higher than in the steady state of the no-bubble economy, while consumption is $0.3 \%$ lower. Thus, the unconditional mean of these endogenous variables is close to steady state.

\footnotetext{
${ }^{12}$ Rolling 200-periods windows of simulated series are used to compute model-predicted moments, as the historical business cycle statistics reported Table 1 pertain to a sample of 200 quarters (see below). For each 200-periods window of artificial data, I computed standard deviations and correlation, using logged series that were HP filtered in the respective window. The Table reports median values, across all windows, of these standard deviations and correlations.
} 
Capital over-accumulation (compared to the no-bubble equilibrium) implies that the bubble economy is 'dynamically inefficient', due to violation of the transversality condition (TVC). Abel et al. (1989) propose an empirical test of dynamic efficiency. Their key insight is that, in a dynamically efficient economy, income generated by capital (i.e. output minus the wage bill) exceeds investment. Abel et al. (1989) show that, in annual US data, this condition is met in all years of their sample (1929-1985). The US historical sample average of the (capital income-investment)/GDP ratio is $13.41 \%$.

In the bubbly Long-Plosser economy, the (capital income - investment)/GDP ratio is positive in $96.4 \%$ of all quarters, but the average ratio is slightly negative, $-0.12 \%$. It should be noted that, in the no-bubble version of the Long-Plosser economy, the (capital income investment)/GDP ratio equals $\alpha(1-\beta)=0.33 \%$, which is only slightly greater than zero, and much smaller than the empirical ratio. Thus, even modest dynamic inefficiency produces a negative capital income - investment gap. As shown below, DSGE models with incomplete capital depreciation can generate bubble equilibria with sizable positive mean capital income investment gaps.

\section{Rational bubbles in an RBC model with incomplete capital depreciation (no TVC)}

I next construct bubble equilibria for a richer non-linear $\mathrm{RBC}$ model with incomplete capital depreciation and variable labor. As before, I postulate that there is no TVC for capital. The following period utility function is assumed: $U\left(C_{t}, L_{t}\right)=\ln \left(C_{t}\right)+\Psi \cdot \ln \left(1-L_{t}\right), \quad \Psi>0$, where $0 \leq L_{t} \leq 1$ are hours worked. The household's total time endowment (per period) is normalized to one, so that $1-L_{t}$ is household leisure. ${ }^{13}$ The resource constraint and the production technology are

$$
C_{t}+K_{t+1}=Y_{t}+(1-\delta) K_{t} \text { with } Y_{t}=\theta_{t}\left(K_{t}\right)^{\alpha}\left(L_{t}\right)^{1-\alpha}
$$

\footnotetext{
${ }^{13}$ The assumed upper bound on hours worked implies that capital and output are bounded, in equilibrium. Some widely used preference specifications (such as $U\left(C_{t}, L_{t}\right)=\ln \left(C_{t}\right)-\Psi \cdot\left(L_{t}\right)^{\mu}, L_{t} \geq 0, \mu>1$ ) do not impose an upper bound on hours worked. Then rational bubbles may induce unbounded growth of hours, capital and output.
} 
where $0<\delta<1$ is the depreciation rate of capital. $\theta_{t}$ (TFP) is exogenous and follows the stationary, bounded $\operatorname{AR}(1)$ process $\ln \left(\theta_{t+1}\right)=\rho \ln \left(\theta_{t}\right)+\varepsilon_{t+1}^{\theta}, 0 \leq \rho<1$, where $\varepsilon_{t+1}^{\theta}$ is a white noise that takes 2 values with equal probability: $\varepsilon_{t+1}^{\theta} \in\left\{-\sigma_{\theta}, \sigma_{\theta}\right\}$, with $\sigma_{\theta} \geq 0$. The standard deviation of the TFP innovation is thus $\sigma_{\theta} \cdot{ }^{14}$

The economy has these efficiency conditions:

$$
\begin{array}{r}
C_{t} \Psi /\left(1-L_{t}\right)=(1-\alpha) \theta_{t}\left(K_{t}\right)^{\alpha}\left(L_{t}\right)^{-\alpha} \text { and } \\
E_{t} \beta\left\{C_{t} / C_{t+1}\right\}\left(\alpha \theta_{t+1}\left(K_{t+1}\right)^{\alpha-1}\left(L_{t+1}\right)^{1-\alpha}+1-\delta\right)=1 .
\end{array}
$$

(11) indicates that the household's marginal rate of substitution between leisure and consumption is equated to the marginal product of labor, while (12) is the date $t$ Euler equation.

(12) shows that hours worked $L_{t}$ are a decreasing function of consumption $C_{t}$. Maximum hours worked $L_{t}=1$ are chosen when consumption is zero. Equations (11) and (12) uniquely pin down consumption and hours worked as functions of $K_{t+1}, K_{t}, \theta_{t}$ :

$$
C_{t}=\gamma\left(K_{t+1}, K_{t}, \theta_{t}\right) \text { and } L_{t}=\eta\left(K_{t+1}, K_{t}, \theta_{t}\right)
$$

Substituting these expressions into the Euler equation gives:

$$
\begin{gathered}
E_{t} H\left(K_{t+2}, K_{t+1}, K_{t}, \theta_{t+1}, \theta_{t}\right)=1 \text {, where } \\
H\left(K_{t+2}, K_{t+1}, K_{t}, \theta_{t+1}, \theta_{t}\right) \equiv \beta\left\{\gamma\left(K_{t+1}, K_{t}, \theta_{t}\right) / \gamma\left(K_{t+2}, K_{t+1}, \theta_{t+1}\right)\right\}\left(\alpha \theta_{t+1}\left(K_{t+1}\right)^{\alpha-1}\left(\eta\left(K_{t+2}, K_{t+1}, \theta_{t+1}\right)\right)^{1-\alpha}+1-\delta\right)
\end{gathered}
$$

is a function that maps $R_{+}^{5}$ into $R$. (The function ' $\mathrm{H}$ ' in (16) differs from the $\mathrm{H}$ function used to define the Euler equation (4) in Sect. 2.)

The model thus boils down to an expectational difference equation in capital. Given a process for capital that solves (15) in all periods, one can use (14) to generate sequences for consumption, hours and output that are consistent with the static equilibrium conditions (11),(12).

The conventional no-bubble model solution that holds under a TVC for capital (which would hold if the economy were inhabited by an infinitely-lived representative household) is described by a unique decision rule $K_{t+1}=\lambda\left(K_{t}, \theta_{t}\right)$ (e.g., Schmitt-Grohé and Uribe (2004)).

\footnotetext{
${ }^{14}$ The discrete distribution of the TFP innovation ensures that the TFP process is bounded, and it simplifies the computation of conditional expectations (Euler equations) in the numerical model solution.
} 
Disregarding the TVC generates additional model solutions. A rational bubble equilibrium is a process $\left\{K_{t}\right\}$ that satisfies (15) but that deviates from the no-bubble decision rule. A rational bubble thus violates the TVC. Throughout the following analysis, I focus on recurrent rational bubbles, i.e. on rational bubbles that are not self-ending and that do not lead to zero capital (economic extinction).

\section{Recurrent rational bubbles}

By analogy to the bubble process in the Long-Plosser economy without TVC (see Sect. 2.2), I consider bubble equilibria in which the capital stock $K_{t+1}$ takes one of two values: $K_{t+1} \in\left\{K_{t+1}^{L}, K_{t+1}^{H}\right\}$ with exogenous probabilities $\pi$ and $1-\pi$, respectively, where $0<\pi<1$, and $K_{t+1}^{L}=\lambda\left(K_{t}, \theta_{t}\right) e^{\Delta}$, for a small constant $\Delta$. With probability $\pi$, the capital stock thus takes a value close to the no-bubble decision rule (as in the bubbly Long-Plosser model).

Throughout the following analysis, I set $\Delta>0$, because a strictly positive $\Delta$ is needed to generate recurrent bubbles. It appears that $\Delta>0$ implies that $K_{t+1}^{L}<K_{t+1}^{H}$ holds, in equilibrium. Thus, I refer to the state in which $K_{t+1}^{L}\left[K_{t+1}^{H}\right]$ is realized as a 'bust' ['boom']. Note also that, with $\Delta>0$, the bubble equilibrium entails capital over-accumulation, compared to the no-bubble economy. As in the Long-Plosser economy (without TVC), bubbles would be self-ending if $\Delta=0$ were assumed; ${ }^{15}$ by contrast, $\Delta<0$ would imply that the economy ultimately reaches zero capital (economic extinction).

At date $t$, agents anticipate that the capital stock set in $t+1, K_{t+2}$, likewise takes one of two values $K_{t+2} \in\left\{K_{t+2}^{L}, K_{t+2}^{H}\right\}$ with probabilities $\pi$ and $1-\pi$, respectively, with $0<\pi<1$ and $K_{t+2}^{L}=\lambda\left(K_{t+1}, \theta_{t+1}\right) e^{\Delta}$. The date $t$ Euler equation (15) can thus be written as:

$$
\pi E_{t} H\left(\lambda\left(K_{t+1}, \theta_{t+1}\right) e^{\Delta}, K_{t+1}, K_{t}, \theta_{t+1}, \theta_{t}\right)+(1-\pi) \cdot E_{t} H\left(K_{t+2}^{H}, K_{t+1}, K_{t}, \theta_{t+1}, \theta_{t}\right)=1 \text { for } K_{t+1} \in\left\{K_{t+1}^{L}, K_{t+1}^{H}\right\}
$$

\footnotetext{
${ }^{15}$ Consider the case $\Delta=0$. Assume that a bust occurs at date $t$, so that $K_{t+1}=K_{t+1}^{L} \equiv \lambda\left(K_{t}, \theta_{t}\right)$. Then Euler equation (17) below is solved by $K_{t+2}^{H}=\lambda\left(K_{t+1}, \theta_{t+1}\right)$, because $E_{t} H\left(\lambda\left(\lambda\left(K_{t}, \theta_{t}\right), \theta_{t+1}\right), \lambda\left(K_{t}, \theta_{t}\right), K_{t}\right)=1$ (see Schmitt-Grohé and Uribe (2004), eqn. (4)). Thus, $K_{t+2}^{H}=K_{t+2}^{L}=\lambda\left(K_{t+1}, \theta_{t+1}\right)$. Irrespective of the date $t+1$ sunspot draw, the date $t+2$ capital stock is hence $K_{t+2}=\lambda\left(K_{t+1}, \theta_{t+1}\right)$. Thus, $K_{t+s+1}=\lambda\left(K_{t+s}, \theta_{t+s}\right)$ will also hold $\forall s>1$. In other terms, when $\Delta=0$, the agent sticks to the no-bubble decision rule in all periods after a bust, i.e. the bubble is 'self-ending'.
} 
Consider an economy that starts in period $t=0$, with an exogenous initial capital stock $K_{0}$. Let $u_{t} \in\{0 ; 1\}$ be an exogenous i.i.d. sunspot that takes values 0 and 1 with probabilities $\pi$ and $1-\pi$, respectively, where $0<\pi<1$. Assume that the sunspot is independent of TFP. Then the following process for capital $\left\{K_{t}\right\}_{t \geq 0}$ is a recurrent rational bubble: $K_{t+2}=K_{t+2}^{L} \equiv \lambda\left(K_{t+1}, \theta_{t}\right) e^{\Delta}$ if $u_{t+1}=0$ and $K_{t+2}=K_{t+2}^{H}$ if $u_{t+1}=1$, for $t \geq 0$, where $K_{t+2}^{H}$ satisfies the date $t$ Euler equation (17).

$K_{1}$ (the capital stock set at $t=0$ ) does not obey the recursion that governs the capital stock in subsequent periods. Thus, $K_{1}$ is indeterminate. In the numerical simulations below, I assume that agents choose $K_{1}=\lambda\left(K_{0}, \theta_{0}\right) e^{\Delta}$. This choice is shown below to be consistent with equilibrium. (The effect of $K_{0}$ and $K_{1}$ on endogenous variables in later periods vanishes as time progresses.) $K_{t+2}^{L}=\lambda\left(K_{t+1}, \theta_{t+1}\right) e^{\Delta} \quad$ (the capital stock chosen in a 'bust' state at date $\mathrm{t}+1$, i.e. when $u_{t+1}=0$ ) depends on $\theta_{t+1}$. I focus on bubble equilibria in which, conditional on date $t$ information, a TFP innovation at $t+1$ has an equiproportional effect on $K_{t+2}^{L}$ and on the 'boom' capital stock, $K_{t+2}^{H}$. Specifically, I postulate that $K_{t+2}^{H}=s_{t}^{H} \cdot K_{t+2}^{L}$, where $s_{t}^{H}>0$ is in the date $t$ information set. Thus, $K_{t+2}^{H}=s_{t}^{H} \cdot \lambda\left(K_{t+1}, \theta_{t+1}\right) e^{\Delta} .{ }^{16}$ This assumption greatly simplifies the specification of bubble equilibria. Substituting the formulae for $K_{t+2}^{L}$ and $K_{t+2}^{H}$ into the Euler equation (17) gives:

$$
\pi E_{t} H\left(\lambda\left(K_{t+1}, \theta_{t+1}\right) e^{\Delta}, K_{t+1}, K_{t}, \theta_{t+1}, \theta_{t}\right)+(1-\pi) \cdot E_{t} H\left(s_{t}^{H} \cdot \lambda\left(K_{t+1}, \theta_{t+1}\right) e^{\Delta}, K_{t+1}, K_{t}, \theta_{t+1}, \theta_{t}\right)=1 .
$$

Solving for bubble equilibria requires solving for $s_{t}^{H}$, in each period. The date $t$ Euler equation (18) implies that $s_{t}^{H}$ is a function of $K_{t+1}, K_{t}, \theta_{t}: s_{t}^{H} \equiv s^{H}\left(K_{t+1}, K_{t}, \theta_{t}\right)$. Given $s_{t}^{H}$, the equilibrium process of capital is fully defined, and consumption, hours and output can be solved using (14),(11).

As in the bubbly Long-Plosser economy (without TVC), the dynamics of capital reflects self-fulfilling variations in agents' expectations about future capital. In a bubble equilibrium, the capital stock evolves in the following sequence:

\footnotetext{
${ }^{16}$ The AR(1) specification of TFP implies $\theta_{t+1}=\left(\theta_{t}\right)^{\rho} \cdot \exp \left(\varepsilon_{t+1}^{\theta}\right)$. The chosen specification of $K_{t+2}^{L}, K_{t+2}^{H}$ implies that $\partial \ln \left(K_{t+2}^{H}\right) / \partial \varepsilon_{t+1}^{\theta}=\partial \ln \left(K_{t+2}^{L}\right) / \partial \varepsilon_{t+1}^{\theta}$; thus, an unexpected change in date $\mathrm{t}+1$ productivity affects $K_{t+2}^{H}$ and $K_{t+2}^{L}$ by the same (relative) amount.
} 
At date $t=0$, agents select the capital stock $K_{1}=\lambda\left(K_{0}, \theta_{0}\right) e^{\Delta}$. They expect (at $t=0$ ) that the capital stock $K_{2}$ (chosen date $t=1$ ) will equal $K_{2}^{L}=\lambda\left(K_{1}, \theta_{1}\right) e^{\Delta}$ or $K_{2}^{H}=s^{H}\left(K_{1}, K_{0}, \theta_{0}\right) \cdot \lambda\left(K_{1}, \theta_{1}\right) e^{\Delta}$, with probabilities $\pi$ and 1- $\pi$, respectively. By construction, the indicated value of $K_{2}^{H}$ solves the date $t=0$ Euler equation. Thus, the stated date $t=0$ expectations (about $K_{2}$ ) sustain the chosen capital stock $K_{1}$.

At $t=1$, agents select the values of the capital stock $K_{2}^{L}$ (if $u_{1}=0$ ) or $K_{2}^{H}$ (if $u_{1}=1$ ) that were just stated. That choice is driven by agents' expectations (at $t=1$ ) about $K_{3}$, the capital stock selected next period $(t=2)$. When $u_{1}=0$ (bust), then agents expect that $K_{3}$ will equal $K_{3}^{L}=\lambda\left(K_{2}^{L}, \theta_{2}\right) e^{\Delta}$ or $K_{3}^{H}=s^{H}\left(K_{2}^{L}, K_{1}, \theta_{1}\right) \cdot \lambda\left(K_{2}^{L}, \theta_{2}\right) e^{\Delta}$, with probabilities $\pi$ and 1- $\pi$, respectively; given these expectations, a choice $K_{2}^{L}$ is consistent with the date $t=1$ Euler equation. In a boom $\left(u_{1}=1\right)$, a choice $K_{2}^{H}$ is sustained by agents' expectation that $K_{3}$ will equal $K_{3}^{L}=\lambda\left(K_{2}^{H}, \theta_{2}\right) e^{\Delta}$ or $K_{3}^{H}=s^{H}\left(K_{2}^{H}, K_{1}, \theta_{1}\right) \cdot \lambda\left(K_{2}^{H}, \theta_{2}\right) e^{\Delta}$, with probabilities $\pi$ and $1-\pi$. The same process is repeated in all subsequent periods.

Due to decreasing returns to capital and bounded TFP, the paths of capital and output are bounded. ${ }^{17}$ An uninterrupted infinite sequence of investment booms (driven by an uninterrupted string of $u=1$ sunspot realizations) would drive the capital towards its upper bound. However, an uninterrupted boom run has zero probability. At any time, the capital stock can revert towards the no-bubble decision rule, with probability $\pi$. For small values of $\Delta$ and a sufficiently high bust probability $\pi$ (as assumed in the simulations discussed below), capital and output remain close to the range of the no-bubble equilibrium, most of the time, and the unconditional mean of endogenous variables is close to the no-bubble steady state.

\footnotetext{
${ }^{17}$ Let $\theta^{\max }$ denote maximum TFP. Capital cannot exceed the stock that would be reached if, in each period consumption were zero, the household worked maximum hours and TFP forever equaled $\theta^{\max }: K_{t} \leq K^{\max }$ where $K^{\max }=\theta^{\max }\left(K^{\max }\right)^{\alpha}+(1-\delta) K^{\max }$
} 


\subsection{Quantitative results}

I again set $\alpha=1 / 3, \beta=0.99$. The capital depreciation rate is set at $\delta=0.025$. The preference parameter $\Psi$ (utility weight on leisure) is set so that the Frisch labor supply elasticity is unity, at steady state. ${ }^{18}$ Parameters in this range are conventional in quarterly macro models (e.g., King and Rebelo (1999)). I set the autocorrelation of TFP at $\rho=0.979$, while the standard deviation of TFP innovations is set at $\sigma_{\theta}=0.72 \%$, as suggested by King and Rebelo (1999). All numerical simulations discussed below assume $\Delta=10^{-6}$. That value generates standard deviations of real activity that are roughly in line with empirical statistics. I report results for two values of the bust probability: $\pi=0.2$ and $\pi=0.5$. Appendix B describes the numerical method used to solve the model.

Table 2 reports simulated business cycle statistics (of HP filtered variables) for several model variants (see Cols. (1)-(10)), as well as historical US business cycle statistics (Col. (11)). Standard deviations (in \%) of output $(Y)$, consumption $(C)$, investment $(I)$ and hours worked $(L)$ are reported, as well as correlations of these variables with output, autocorrelations and mean values. The Table also reports the mean of the (capital income-investment)/GDP ratio, as well as the fraction of periods in which this ratio is positive.

Cols. (1)-(4) of Table 2 pertain to bubble model variants with just bubble (sunspot) shocks (constant TFP assumed). Cols. (5)-(8) consider bubble model variants with simultaneous bubble and TFP shocks. Cols. (9)-(10) assume a no-bubble model (TVC imposed) with TFP shocks. ${ }^{19}$ Cols. (1), (3), (5),(7) assume a bust probability $\pi=0.5$, while Cols. (2),(4),(6),(8) assume $\pi=0.2$. Cols. labelled 'Unit Risk Aversion' (or 'Unit RA') assume log utility, $U\left(C_{t}, L_{t}\right)=\ln \left(C_{t}\right)+\Psi \cdot \ln \left(1-L_{t}\right)$. Columns labelled 'High RA' assume greater risk aversion: $U\left(C_{t}, L_{t}\right)=\ln \left(C_{t}-\bar{C}\right)+\Psi \cdot \ln \left(1-L_{t}\right)$, where $\bar{C}$ is a constant that is set at 0.8 times steady state consumption. The 'High RA' preferences imply that consumption has a strictly positive lower bound: $C_{t} \geq \bar{C}>0$. In the 'High RA' case, the coefficient of relative risk aversion is 5 , at steady

\footnotetext{
${ }^{18}$ (12) implies that the Frisch labor supply elasticity (LSE) with respect to the real wage (marginal product of labor) is $L S E=(1-L) / L$ at the steady state, where $L$ are steady state hours worked. $\Psi$ is set such that $L=0.5$, as then $L S E=1$.

19 The no-bubble model is solved using a second-order Taylor approximation, as it is well-know that this approximation is very accurate for standard (no-bubble) RBC models (e.g., Kollmann et al. (2011a,b)).
} 
state consumption (risk aversion is higher for consumption levels below steady state consumption).

Fig. 3 shows simulated paths of output ( $Y$, continuous black line), consumption $(C$, red dashed line), investment ( $I$, dark blue dash-dotted line) and hours worked ( $L$, light blue dotted line). Panel (i) (for $i=1, . ., 10$ ) of Fig. 3 assumes the model variant considered in Col. (i) of Table 2. The $Y, C$ and $I$ series plotted in Fig. 3 are normalized by steady state output (of the no-bubble economy); hours worked $(L)$ are normalized by steady state hours. The same sequence of sunspots is fed into each of the bubble model variants with the same bust probability; also, the same sequence of TFP innovations is fed into each model variant with TFP shocks.

Col. (1) of Table 2 assumes a variant of the bubble model with unit risk aversion and a bust probability $\pi=0.5$; fluctuations are just driven by bubble shocks (constant TFP assumed). The predicted standard deviations of output, consumption, investment and hours worked are $0.49 \%, 1.08 \%, 4.29 \%$ and $0.74 \%$, respectively. Consistent with the data, investment is predicted to be more volatile than output. However, the model (with unit risk aversion) predicts that consumption is more volatile than output, which is counterfactual. The model also predicts that consumption is negatively correlated with output (a positive bubble shock raises investment; this crowds out consumption, which raises labor supply and thereby boosts output). ${ }^{20}$ However, the model predicts that investment and hours worked are strongly procyclical, as is consistent with the data. In the model, output, consumption, investment and hours worked are positively serially correlated, but the predicted autocorrelations (about 0.35) are smaller than the empirical autocorrelations (about 0.9).

Panel (1) of Fig. 3 shows simulated paths driven just by bubble shocks, for the bubble model with unit risk aversion and $\pi=0.5$. We see that the bubble equilibrium generates booms in output, labor hours and investment that are relatively infrequent and brief. This explains the low predicted autocorrelation of real activity. In most periods, output, consumption, investment and output remain close to (but slightly above) the steady state levels of the no-bubble economy.

A lower bust probability $\pi=0.2$ generates more persistent booms in real activity. For an economy with just bubble shocks, this is illustrated in Col. (2) of Table 2, where a unit risk aversion and $\pi=0.2$ are assumed (see also Panel (2) of Fig. 3). The autocorrelation of real activity is now about 0.6 . Consumption is again predicted to be more volatile than output.

\footnotetext{
${ }^{20}$ This is a familiar feature of flex-wage models driven by investment shocks; e.g., Coeurdacier et al. (2011).
} 
Model variants with 'High Risk Aversion (RA)' utility generate less consumption volatility - those variants capture the fact that consumption is less volatile than output; see Cols. (3) and (4) of Table 2 (and Panels (3) and (4) of Fig. 3), where $\pi=0.5$ and $\pi=0.2$ are assumed, respectively.

In summary, the bubble model versions with constant TFP can generate a realistic volatility of real activity and of aggregate demand components and high serial correlation.

The no-bubble model driven by stochastic TFP shocks underpredicts the volatility of real activity, but it captures the fact that consumption is less volatile than output, while investment is more volatile (see Table 2, Cols. (9) and (10)). In the no-bubble model, consumption and investment are pro-cyclical; furthermore, real activity is highly serially correlated

The bubble economy with joint bubble shocks and TFP shocks generates fluctuations in real activity that are more volatile than the fluctuations exhibited by the no-bubble economy (see Table 2, Cols. (5)-(8)). In this sense, the bubble equilibrium with TFP shocks is closer to the historical business cycle moments.

Panels (5)-(10) of Fig. 3 show that the effect of bubbles on the simulated series is clearly noticeable (compared to the simulated series of the no-bubble economy with TFP shocks): the bubble economy exhibits more rapid, but short-lived, increases in investment, hours worked and output.

In the bubble economies considered here, the unconditional mean of endogenous variables is again close to the no-bubble steady state (as in the Long-Plosser economy with bubbles studied in Sect. 2) ${ }^{21}$ For all variants of the bubble economy with incomplete capital depreciation considered in Table 2, the average (capital income - investment)/GDP ratio is positive and large (unlike in the Long-Plosser model); the average ratio ranges between $8.5 \%$ and $9.2 \%$, and it is only slightly smaller than the value of that ratio in the no-bubble steady state, $9.59 \%{ }^{22}$ Capital income exceeds investment in close to $100 \%$ of all periods. This highlights the difficulty of detecting dynamic inefficiency (as discussed above).

\footnotetext{
${ }^{21}$ In Tables 2-4, mean values of $Y, C, I, L$ are reported as \% deviations from the no-bubble steady state. The mean (capital income - investment)/GDP ratio (see below) is not expressed as a \% deviation from steady state.

${ }^{22}$ In the bubble economy, the steady state (capital income - investment)/GDP ratio is $\alpha r /(\delta+r)$ where $r=(1-\beta) / \beta$ is the steady state interest rate.
} 


\section{Rational bubbles in a Dellas two-country RBC economy (no TVC)}

I next study bubbles in open economies. This Section considers Dellas' (1986) two-country RBC model. The Dellas model is a two-country version of the Long and Plosser (1983) model, as it also assumes log utility, Cobb-Douglas production functions and full capital depreciation. Like the Long-Plosser model, the Dellas model has an exact closed form solution. I construct rational bubbles that arise when there is no transversality condition (TVC), in the Dellas economy.

Assume a world with two symmetric countries, referred to as Home $(\mathrm{H})$ and Foreign $(\mathrm{F})$, respectively. The household of country $i=H, F$ has log preferences of the type assumed in the closed economy RBC model of Sect. 3. Thus, her period utility function is: $U\left(C_{i, t}, L_{t}\right)=\ln \left(C_{i, t}\right)+\Psi \cdot \ln \left(1-L_{i, t}\right), \quad \Psi>0, \quad$ where $C_{i, t}$ and $L_{i, t}$ are consumption and hours worked. Each country is specialized in the production of a distinct tradable intermediate good. Country i's intermediate good production function is $Y_{i, t}=\theta_{i, t}\left(K_{i, t}\right)^{\alpha}\left(L_{i, t}\right)^{1-\alpha}$, where $Y_{i, t}, \theta_{i, t}, K_{i, t}$ are the intermediate good output, TFP and capital in country $i$. Capital and labor are immobile internationally. TFP is exogenous and follows a bounded Markov process. The country $i$ household combines local and imported intermediates into a non-tradable final good, using the Cobb-Douglas aggregator

$$
Z_{i, t}=\left(y_{i, t}^{i} / \xi\right)^{\xi} \cdot\left(y_{i, t}^{j} /(1-\xi)\right)^{1-\xi}, i \neq j
$$

where $y_{i, t}^{j}$ is the amount of input $j$ used by country $i$. There is local bias in final good production: $\frac{1}{2}<\xi<1$. The country $i$ final good is used for consumption, $C_{i, t}$, and investment, $I_{i, t}: Z_{i, t}=C_{i, t}+I_{i, t}$. Due to full capital depreciation, the capital stock at $t+1$ equals investment at $t: K_{i, t+1}=I_{i, t}$.

At date $t$, the price of country $i$ 's final good $\left(P_{i, t}\right)$ equals its marginal cost:

$$
P_{i, t}=\left(p_{i, t}\right)^{\xi} \cdot\left(p_{j, t}\right)^{1-\xi}, i \neq j,
$$

where $p_{j, t}$ is the price of intermediate $\operatorname{good} j$. Country $i$ 's demand functions for domestic and imported intermediate goods are given by:

$$
y_{i, t}^{i}=\xi \cdot\left(p_{i, t} / P_{i, t}\right)^{-1} Z_{i, t} \text { and } y_{i, t}^{j}=(1-\xi) \cdot\left(p_{j, t} / P_{i, t}\right)^{-1} Z_{i, t} \text {, for } j \neq i .
$$

Market clearing for intermediate goods requires

$$
y_{H, t}^{i}+y_{F, t}^{i}=Y_{i, t} \text {, for } i=H, F \text {. }
$$


Country $i$ 's terms of trade and real exchange rate are defined as $q_{i, t} \equiv p_{i, t} / p_{j, t}$ and $R E R_{i, t} \equiv P_{i, t} / P_{j, t}$, with $i \neq j$, respectively. Thus, increases in $q_{i, t}$ and $R E R_{i, t}$ represent an improvement in country $i$ 's terms of trade, and an appreciation of its real exchange rate.

The model assumes complete international financial markets, so that consumption risk is efficiently shared across countries. In equilibrium, the ratio of Home to Foreign households' marginal utilities of consumption is, thus, proportional to the Home real exchange rate (Kollmann, 1991, 1995; Backus and Smith, 1993). Under log utility, this implies that Home consumption spending is proportional to Foreign consumption spending: $P_{H, t} C_{H, t}=\Lambda \cdot P_{F, t} C_{F, t}$, where $\Lambda$ is a date- and state-invariant term that reflects the (relative) initial wealth of the two countries. In what follows, I assume that the two countries have the same initial wealth, and I hence set $\Lambda=1$. Thus:

$$
P_{H, t} C_{H, t}=P_{F, t} C_{F, t} .
$$

Each household equates the marginal rate of substitution between leisure and consumption to the marginal product of labor, expressed in units of consumption, which implies

$$
C_{i, t} \Psi /\left(1-L_{i, t}\right)=\left(p_{i, t} / P_{i, t}\right)(1-\alpha)\left(Y_{i, t} / L_{i, t}\right) .
$$

The Euler equation of the country $i$ household for domestic physical capital is:

$$
E_{t} \beta\left(C_{i, t} / C_{i, t+1}\right)\left[\left(p_{i, t+1} / P_{i, t+1}\right) \alpha Y_{i, t+1} / K_{i, t+1}\right]=1,
$$

where the term in square brackets is country $i$ 's marginal product of capital at date $t+1$, expressed in units of the country $i$ final good. Substitution of the intermediate good demand functions (21) into the market clearing condition for intermediates (22) gives:

$$
\begin{aligned}
p_{H, t} Y_{H, t} & =\xi \cdot\left(P_{H, t} C_{H, t}+P_{H, t} K_{H, t+1}\right)+(1-\xi) \cdot\left(P_{F, t} C_{F, t}+P_{F, t} K_{F, t+1}\right), \\
p_{F, t} Y_{F, t} & =(1-\xi) \cdot\left(P_{H, t} C_{H, t}+P_{H, t} K_{H, t+1}\right)+\xi \cdot\left(P_{F, t} C_{F, t}+P_{F, t} K_{F, t+1}\right) .
\end{aligned}
$$

Using the risk sharing condition (23), we can state (26) as:

$$
\begin{gathered}
p_{H, t} Y_{H, t}=P_{H, t} C_{H, t}+\xi \cdot P_{H, t} K_{H, t+1}+(1-\xi) \cdot P_{F, t} K_{F, t+1}, \\
p_{F, t} Y_{F, t}=P_{F, t} C_{F, t}+(1-\xi) \cdot P_{H, t} K_{H, t+1}+\xi \cdot P_{F, t} K_{F, t+1} .
\end{gathered}
$$

The labor supply equation (24) and the Euler equation (25) may be formulated as:

$$
L_{i, t} /\left(1-L_{i, t}\right)=((1-\alpha) / \Psi) \cdot p_{i, t} Y_{i, t} /\left(P_{i, t} C_{i, t}\right) \text { for } i=H, F
$$


and $\alpha \beta E_{t}\left\{\left(P_{i, t} C_{i, t}\right) /\left(P_{i, t+1} C_{i, t+1}\right)\right\}\left(p_{i, t+1} Y_{i, t+1}\right) /\left(P_{i, t} K_{i, t+1}\right)=1$ for $i=H, F$.

These equations can be expressed in terms of Home and Foreign investment/consumption ratios and of nominal output/consumption ratios:

$$
\begin{gathered}
\kappa_{i, t} \equiv P_{i, t} K_{i, t+1} /\left(P_{i, t} C_{i, t}\right) \text { for } i=H, F ; \\
g_{i, t} \equiv p_{i, t} Y_{i, t} /\left(P_{i, t} C_{i, t}\right) \text { for } i=H, F .
\end{gathered}
$$

The market clearing, labor supply and Euler conditions (27), (28) and (29) give

$$
\begin{gathered}
g_{H, t}=1+\xi \kappa_{H, t}+(1-\xi) \kappa_{F, t}, \quad g_{F, t}=1+(1-\xi) \kappa_{H, t}+\xi \kappa_{F, t}, \\
L_{i, t} /\left(1-L_{i, t}\right)=((1-\alpha) / \Psi) \cdot g_{i, t} \text { for } i=H, F, \\
\text { and } \quad \alpha \beta E_{t} g_{i, t+1}=\kappa_{i, t} \text { for } i=H, F .
\end{gathered}
$$

Using the market clearing conditions (32), we can write the Euler equations (34) as:

$$
\alpha \beta \cdot E_{t}\left(1+\xi \kappa_{H, t+1}+(1-\xi) \kappa_{F, t+1}\right)=\kappa_{H, t} \text { and } \alpha \beta \cdot E_{t}\left(1+(1-\xi) \kappa_{H, t+1}+\xi \kappa_{F, t+1}\right)=\kappa_{F, t} .
$$

The deterministic steady state value of the Home and Foreign investment/consumption ratios is $\kappa \equiv \alpha \beta /(1-\alpha \beta)$. Let $\widetilde{\kappa_{i, t}} \equiv \kappa_{i, t}-\kappa$ denote the deviation of $\kappa_{i, t}$ from its steady state value. The Euler equations (35) imply:

$$
\alpha \beta \cdot E_{t}\left(\widetilde{\xi \kappa_{H, t+1}}+(1-\xi) \widetilde{\kappa_{F, t+1}}\right)=\widetilde{\kappa_{H, t}} \text { and } \alpha \beta \cdot E_{t}\left((1-\xi) \widetilde{\kappa_{H, t+1}}+\xi \widetilde{\kappa_{F, t+1}}\right)=\widetilde{\kappa_{F, t}} .
$$

Therefore, $A \cdot\left[\begin{array}{l}E_{t} \widetilde{\kappa_{H, t+1}} \\ E_{t} \widetilde{\kappa_{F, t+1}}\end{array}\right]=\left[\begin{array}{c}\widetilde{\kappa_{H, t}} \\ \widetilde{\kappa_{F, t}}\end{array}\right]$, where $A \equiv \alpha \beta \cdot\left[\begin{array}{cc}\xi & 1-\xi \\ 1-\xi & \xi\end{array}\right]$. Hence,

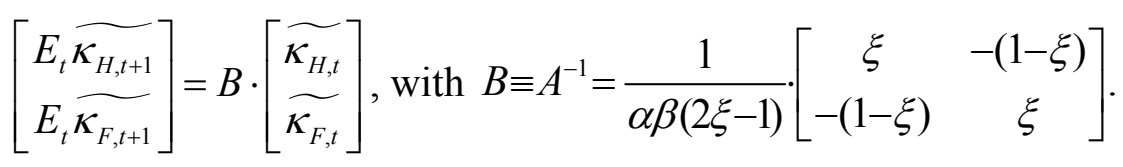

The two eigenvalues of the matrix $B$ are $\lambda_{S} \equiv 1 /(\alpha \beta)$ and $\lambda_{D} \equiv 1 /(\alpha \beta(2 \xi-1))$. Both eigenvalues are greater than 1 , as $0.5<\xi<1$. Hence, the only non-explosive solution of (37) is given by $\widetilde{\kappa_{i, t}}=0 \forall t$ and thus by $\kappa_{i, t}=\alpha \beta /(1-\alpha \beta), \forall t, i=H, F$. This solution satisfies Home and Foreign TVCs (that hold if Home and Foreign representative households are infinitely lived). Dellas (1986) focuses on this no-bubble solution. 


\subsection{Rational bubbles}

In what follows, I study rational bubble equilibria with $\widetilde{\kappa_{i, t}} \neq 0$ that arise when there is no TVC. I show that the Dellas model has bubble equilibria that feature recurrent, bounded fluctuations of capital, hours worked, output and consumption. These equilibria do not converge to zero capital or zero consumption corners. If the Home or Foreign capital stock ever fell to zero, then capital and output in both countries would remain stuck at zero in all subsequent periods. Such trajectories seem empirically irrelevant. The goal of the analysis here is to construct bubble equilibria with recurrent fluctuations in real activity, and thus I focus on bubbles with a strictly positive capital process.

As shown below, any strictly positive process for Home and Foreign capital that satisfies the Euler equations (35),(36) has to be such that

$$
\widetilde{\kappa_{H, t}}=\widetilde{\kappa_{F, t}} \geq 0 \forall t \text {. }
$$

Thus, the bubbly investment/consumption ratio has to be always at least as large as the steady state ratio. Note also that, in the two-country model, bubble equilibria feature capital overaccumulation (as was the case in the closed economy models studied in previous Sections). Also, the bubble process has to be identical across the two countries. To understand this, let $S_{t} \equiv \widetilde{\kappa_{H, t}}+\widetilde{\kappa_{F, t}}$ and $D_{t} \equiv \widetilde{\kappa_{H, t}}-\widetilde{\kappa_{F, t}}$ respectively denote the sum and the difference of the two countries' investment/consumption ratios, expressed as deviations from steady state. (37) implies $E_{t} S_{t+1}=\lambda_{S} \cdot S_{t}$ and $E_{t} D_{t+1}=\lambda_{D} \cdot D_{t}$, where $\lambda_{S}$ and $\lambda_{D}$ are the eigenvalues of the matrix $B$ (see (37)). Note that $\widetilde{\kappa_{H, t}}=\frac{1}{2} \cdot\left(D_{t}+S_{t}\right)$ and $\widetilde{\kappa_{F, t}}=\frac{1}{2} \cdot\left(S_{t}-D_{t}\right)$. Hence,

$$
E_{t} \widetilde{\kappa_{H, t+s}}=\frac{1}{2} \cdot\left(\lambda_{S}\right)^{s}\left\{S_{t}+(1 /(2 \xi-1))^{s} D_{t}\right\} \text { and } \widetilde{E_{t} \widetilde{\kappa_{F, t+s}}}=\frac{1}{2}\left(\lambda_{S}\right)^{s}\left\{S_{t}-(1 /(2 \xi-1))^{s} D_{t}\right\} \text {, }
$$

where I use the fact that $\lambda_{D}=\lambda_{S} /(2 \xi-1) . \quad 0.5<\xi<1$ implies $1 /(2 \xi-1)>1$ and thus $\lambda_{D}>\lambda_{S}$. A necessary condition for non-negativity of $\kappa_{H, \tau}$ and $\kappa_{F, \tau}$ in all future dates and states $\tau \geq$ is $D_{t}=0$ and $S_{t} \geq 0$. This implies (38). ${ }^{23}$

${ }^{23} D_{t} \neq 0$ would imply $\lim _{s \rightarrow \infty} E_{t} \widetilde{\kappa_{H, t+s}}=-\infty$ or $\lim _{s \rightarrow \infty} E_{t} \widetilde{\kappa_{F, t+s}}=-\infty$. With strictly positive probability, $\kappa_{H, \tau}$ or $\kappa_{F, \tau}$ would thus be negative at some date(s) $\tau \geq$ t. Setting $D_{t}=0$ in (39) shows that $S_{t}<0$ would imply $\lim _{s \rightarrow \infty} E_{t} \widetilde{\kappa_{H, t+s}}=-\infty$ and $\lim _{s \rightarrow \infty} E_{t} \widetilde{\kappa_{F, t+s}}=-\infty$, so that $\kappa_{H, \tau}<0$ and/or $\kappa_{F, \tau}<0$ would hold with positive probability at some date(s) $\tau$ t. 
Intuitively, a (positive) bubble that e.g. occurs solely in the Home country $\left(\widetilde{\kappa_{H, t}}>0\right)$ would trigger an improvement in the Home terms of trade, and a rise in the Home trade deficit, due to growing intermediate imports by Home, fueled by the bubble-induced boom in Home investment. This would put Foreign investment on a downward trajectory. If the Home bubble lasts sufficiently long, the Foreign capital stock can ultimately reach zero.

More formally, we can note from the Foreign Euler condition shown in (36) (see second equation) that if $\widetilde{\kappa_{H, t}}>0$ and $E_{t} \widetilde{\kappa_{H, t+1}}>0$ hold, then $\widetilde{\kappa_{F, t}}=E_{t} \widetilde{\kappa_{F, t+1}}=0$ is impossible. Thus a bubble cannot occur just in country H. But why do bubbles have to be identical in the two countries?

The country $i$ Euler equation prescribes that $i$ 's investment/consumption ratio at date $t$ equals the country's expected date $t+1$ output/consumption ratio multiplied by the factor $0<\alpha \beta<1$ (see (34)). The future output/consumption ratio equals 1 plus a weighted average of future domestic and foreign investment/consumption ratios, with weights $\xi$ and $1-\xi$, respectively (see (32)). If Home and Foreign had identical final good technologies, i.e. $\xi=1 / 2$ (no local spending bias), the date $t$ investment/consumption ratio would thus be identical across countries, irrespective of the expected date $t+1$ investment/consumption ratios. With a local spending bias $(1 / 2<\xi<1)$, the difference between Home and Foreign investment/consumption ratios at date $t$ is smaller (in absolute value) than the expected cross-country difference of investment/consumption at $t+1$ (as $1 / \lambda_{D}<1$ ). Any difference between domestic and foreign investment/consumption ratios at date $t \quad\left(D_{t} \neq 0\right)$ would trigger a larger expected difference in period $t+1$; thus, the expected cross-country difference would explode, and that at a faster rate than the sum of these two-country's investment/consumption ratios (as $\lambda_{D}>\lambda_{S}$ ). This would induce violations of the non-negativity constraint on capital in future periods $\tau>t$. (As discussed below, local bubbles can occur under financial autarky. However, local bubbles trigger violations of the international risk sharing condition (23)).

The subsequent discussion thus assumes that (38) holds. Let $\kappa_{t}=\kappa_{H, t}=\kappa_{F, t}$ denote the common investment/consumption ratio in both countries, and let $\widetilde{\kappa}_{t} \equiv \kappa_{t}-\kappa$ be its deviation from the steady state ratio $\kappa$. The Home and Foreign Euler equations (36) imply

$$
\alpha \beta E_{t} \widetilde{\kappa_{t+1}}=\widetilde{\kappa_{t}} .
$$




\section{Recurrent rational bubbles}

By analogy to the bubble equilibria discussed in previous Sections, I assume that $\widetilde{\kappa_{t+1}}$ takes two values: $\widetilde{\kappa_{t+1}} \in\left\{\Delta, \widetilde{\kappa_{t+1}^{H}}\right\}$ with exogenous probabilities $\pi$ and $1-\pi$, respectively, with $0<\pi<1$ and $\Delta>0 . \Delta>0$ ensures the existence of recurrent (non-ending) bubbles, i.e. of bubbles that are not self-ending and that do not lead to zero capital. (As in the bubbly Long-Plosser model, a bubble process with $\Delta<0$ would ultimately hit the zero capital corner. $\Delta=0$ would imply that the bubble is self-ending; a bust $\widetilde{\kappa_{t}}=0$ would imply $\widetilde{\kappa_{\tau}}=0 \forall \tau>t$.)

Consider a world economy that starts in period $t=0$, with exogenous initial capital stocks $K_{H, 0}, K_{F, 0}$. Let $u_{t} \in\{0 ; 1\}$ be an exogenous i.i.d. sunspot that takes values 0 and 1 with probabilities $\pi$ and $1-\pi$, respectively, where $0<\pi<1$. Then the following process for the investment/consumption ratio $\left\{\widetilde{\kappa}_{t}\right\}_{t \geq 0}$ is a recurrent rational bubble: $\widetilde{\kappa_{t+1}}=\Delta$ if $u_{t+1}=0$ and $\kappa_{t+1}=\widetilde{\kappa_{t+1}^{H}}$ if $u_{t+1}=1$, for $\mathrm{t} \geq 0$, where $\widetilde{\kappa_{t+1}^{H}}$ solves the date $t$ Euler equation (40). Note that (40) implies $\alpha \beta\left\{\pi \Delta+(1-\pi) \widetilde{\kappa_{t+1}^{H}}\right\}=\widetilde{\kappa_{t}}$, and so $\widetilde{\kappa_{t+1}^{H}}=\left(\widetilde{\kappa_{t}}-\alpha \beta \pi \Delta\right) /(\alpha \beta(1-\pi))$. If $\widetilde{\kappa_{t}} \geq \Delta$ holds, then $\widetilde{\kappa_{t+1}^{H}}>\widetilde{\kappa_{t}}$

The investment/consumption ratio in the initial period, $\widetilde{\kappa}_{0}$, does not obey the recursion that governs the investment/consumption ratio in subsequent periods. Thus, $\widetilde{\kappa_{0}}$ is indeterminate. However, $\widetilde{\kappa_{0}} \geq \Delta$ has to hold to ensure that $\widetilde{\kappa_{t}} \geq \Delta \quad \forall t>0$.

Given the $\left\{\kappa_{t}\right\}$ process, one can solve for the real exchange rate, hours worked, consumption, investment and output in both countries, using the static equilibrium conditions (26)-(28) and (30)-(33). Note that the $\left\{\kappa_{t}\right\}$ process is unbounded. Nevertheless, as shown below, capital, hours, output and consumption are bounded. (33) implies that labor hours in country $i$ are a function of the (nominal) output/consumption ratio $g_{i, t}$. In equilibrium, both countries have the same output/consumption ratio, as $g_{i, t}=1+\kappa_{t}$ holds for $i=H, F$. Equilibrium hours worked are, thus, identical across countries:

$$
L_{i, t}=L_{t} \equiv\left(1+\kappa_{t}\right) /\left\{1+\kappa_{t}+\Psi /(1-\alpha)\right\} \text { for } i=H, F,
$$

and country $i$ output is: 


$$
Y_{i, t}=\theta_{i, t}\left(K_{i, t}\right)^{\alpha}\left(L_{t}\right)^{1-\alpha} .
$$

$\kappa_{H, t}=\kappa_{F, t}$ implies that investment and output, valued at market prices, are equated across countries: $P_{H, t} K_{H, t+1}=P_{F, t} K_{F, t+1}$ and $p_{H, t} Y_{H, t}=p_{F, t} Y_{F, t}$ (from (23), (30) and (31)). Because consumption spending is likewise equated across countries (see (23)), net exports are zero. Country $i$ 's terms of trade equal the inverse of $i$ 's relative output: $q_{i, t} \equiv p_{i, t} / p_{j, t}=Y_{j, t} / Y_{i, t}$ with $j \neq i$. The real exchange rate is $\operatorname{RER} R_{i, t}=\left(q_{i, t}\right)^{2 \xi-1}$. (31) implies $C_{i, t}=\left(1 /\left(1+\kappa_{t}\right)\right)\left(p_{i, t} / P_{i, t}\right) Y_{i, t}$. Note that $p_{i, t} / P_{i, t}=\left(q_{i, t}\right)^{1-\xi}=\left(Y_{j, t} / Y_{i, t}\right)^{1-\xi}$ with $j \neq i$. Thus:

$$
C_{H, t}=\left(1 /\left(1+\kappa_{t}\right)\right)\left(Y_{H, t}\right)^{\xi}\left(Y_{F, t}\right)^{1-\xi} \text { and } C_{F, t}=\left(1 /\left(1+\kappa_{t}\right)\right)\left(Y_{H, t}\right)^{1-\xi}\left(Y_{F, t}\right)^{\xi} \text {. }
$$

Finally, note that $K_{i, t+1}=\kappa_{t} C_{i, t}$ (see (30)). Therefore, date $t$ investment is:

$$
K_{H, t+1}=\left(\kappa_{t} /\left(1+\kappa_{t}\right)\right)\left(Y_{H, t}\right)^{\xi}\left(Y_{F, t}\right)^{1-\xi} \text { and } K_{F, t+1}=\left(\kappa_{t} /\left(1+\kappa_{t}\right)\right)\left(Y_{H, t}\right)^{1-\xi}\left(Y_{F, t}\right)^{\xi} .
$$

Hours worked, investment and output at date $t$ are increasing functions of $\kappa_{t}$, while consumption is decreasing in $\kappa_{t}$.

(44) implies that logged capital follows the vector autoregression

$$
\left[\begin{array}{l}
\ln \left(K_{H, t+1}\right) \\
\ln \left(K_{F, t+1}\right)
\end{array}\right]=\left[\begin{array}{cc}
\xi \alpha & (1-\xi) \alpha \\
(1-\xi) \alpha & \xi \alpha
\end{array}\right] \cdot\left[\begin{array}{l}
\ln \left(K_{H, t}\right) \\
\ln \left(K_{F, t}\right)
\end{array}\right]+\left[\begin{array}{c}
\omega_{H}\left(\theta_{H, t}, \theta_{F, t} \kappa_{t}\right) \\
\omega_{F}\left(\theta_{H, t}, \theta_{F, t}, \kappa_{t}\right)
\end{array}\right],
$$

where $\omega_{i}\left(\theta_{H, t}, \theta_{F, t}, \kappa_{t}\right) \equiv \ln \left\{\left(\kappa_{t} /\left(1+\kappa_{t}\right)\right)\left(L_{t}\right)^{1-\alpha}\left(\theta_{i, t}\right)^{\xi}\left(\theta_{j, t}\right)^{1-\xi}\right\} \quad$ (with $\left.j \neq i\right)$ is a function of hours worked, of TFP in the two countries, and of $\kappa_{t}$. Note that $\kappa_{t} \geq \Delta+\alpha \beta /(1-\alpha \beta) . \kappa_{t} /\left(1+\kappa_{t}\right)$ is strictly positive and bounded: $0<\{\Delta+\alpha \beta /(1-\alpha \beta)\} /\{1+\Delta+\alpha \beta /(1-\alpha \beta)\} \leq \kappa_{t} /\left(1+\kappa_{t}\right)<1$, and so are hours worked (see (41)). Given the assumption that TFP is bounded, $\omega_{H, t}$ and $\omega_{F, t}$ are bounded too. The eigenvalues of the autoregressive matrix of the law of motion (45) of log capital ( $\alpha$ and $\alpha(2 \xi-1)$ ) are strictly positive, but smaller than 1 . Thus, the capital stock in each country is stable and bounded, and so are output, hours worked and consumption. 


\subsection{Quantitative results}

Table 3 reports simulated business statistics for the two-country Dellas model with bubbles (Cols. (1)-(3)); also shown are historical business statistics (Col. (4)). Historical standard deviations, correlations with GDP and autocorrelations are based on US data, 1968q1-2017q4; historical cross-country correlations are correlations between the US and the Euro Area, 1970q1-2017q4 (quarterly data for the Euro Area aggregate are only available from 1970q1). Empirically, the US real exchange rate is about 2.5 times as volatile as US output; US net exports (normalized by GDP) are countercyclical. Real activity is positively correlated across the US and the Euro Area. The cross-country correlations of output and investment are close to 0.5 ; the cross-country correlations of consumption and employment are slightly lower (0.39).

In the numerical model simulations, the capital share, and the subjective discount rate are again set at $\alpha=1 / 3$ and $\beta=0.99$. The share of spending devoted to domestic intermediates is set at $\xi=0.9 .^{24} \mathrm{I}$ set the bust probability at $\pi=0.5 . \Delta$ is set at $2.227 \times 10^{-6}$, as this parallels the calibration of the investment bust in the bubbly Long-Plosser closed economy model (see Sect. 2 ), and generates a realistic volatility of output. ${ }^{25}$

Versions of the two-country model with TFP shocks assume that Home and Foreign TFP follow the (symmetric) autoregressive process that Backus et al. (1994) estimated using quarterly TFP series for the US and an aggregate of European economies:

$$
\left[\begin{array}{l}
\ln \theta_{H, t+1} \\
\ln \theta_{F, t+1}
\end{array}\right]=\left[\begin{array}{ll}
.906 & .088 \\
.088 & .906
\end{array}\right] \cdot\left[\begin{array}{l}
\ln \theta_{H, t} \\
\ln \theta_{F, t}
\end{array}\right]+\left[\begin{array}{c}
\varepsilon_{H, t+1}^{\theta} \\
\varepsilon_{F, t+1}^{\theta}
\end{array}\right],
$$

\footnotetext{
${ }^{24}$ This is consistent with the fact that the mean US trade share (0.5×(imports+exports)/GDP) was $10 \%$ in $1968-2017$. ${ }^{25} \Delta=2.227 \times 10^{-6}$ implies that, in a bust, the ratio of investment spending divided by nominal GDP, $Z_{i, t} \equiv P_{i, t} K_{i, t+1} /\left(p_{i, t} Y_{i, t}\right)$ exceeds its steady state value $\alpha \beta$ by the amount $10^{-6}$, as assumed in the calibration of the bubbly Long-Plosser economy. Note that $Z_{i, t}=\kappa_{t} /\left(1+\kappa_{t}\right)$ for $i=H, F$. Thus, the investment/output ration is equated across countries: $Z_{t} \equiv Z_{H, t}=Z_{F, t}$. Up to a first-order approximation, $\kappa_{t}-\kappa=(1-\alpha \beta)^{-2} \times\left(Z_{t}-Z\right)$, where $\kappa \equiv \alpha \beta /(1-\alpha \beta)$ and $Z \equiv \alpha \beta$ are steady state values of $\kappa_{t}$ and $Z_{t}$, respectively. As $(1-\alpha \beta)^{-2} \cong 2.227$, we have that $\kappa_{t}-\kappa=2.227 \times\left(Z_{t}-Z\right)$. Thus, $\kappa^{L}-\kappa=2.227 \times\left(Z^{L}-Z\right)$, where $\kappa^{L}$ and $Z^{L}$ denote bust values. The calibration of the Long-Plosser model (see Sect. 2) sets $Z^{L}-Z=10^{-6}$. Thus, a calibration of the two-country model with $\Delta \equiv \kappa^{L}-\kappa=2.227 \times 10^{-6}$ parallels that of the bubbly Long-Plosser model.
} 
where $\quad \varepsilon_{H, t+1}^{\theta}, \varepsilon_{F, t+1}^{\theta} \quad$ are $\quad$ white noises $\quad$ with $\quad \operatorname{Std}\left(\varepsilon_{H, t+1}^{\theta}\right)=\operatorname{Std}\left(\varepsilon_{F, t+1}^{\theta}\right)=0.852 \% \quad$ and $\operatorname{Corr}\left(\varepsilon_{H, t+1}^{\theta}, \varepsilon_{F, t+1}^{\theta}\right)=0.258$. ${ }^{26}$ Thus, TFP is a highly persistent process, and there are delayed positive cross-country spillovers (positive off-diagonal elements of the autoregressive matrix); also, productivity innovations are positively correlated across countries.

Col. 1 of Table 3 considers a version of the bubble economy with just bubble shocks (constant TFP assumed). Col.2 assumes a bubble model with joint bubble and TFP shocks, while Col. 3 assumes a conventional no-bubble Dellas economy (TVC imposed) with TFP shocks.

In the bubble model with constant TFP, output, consumption, investment and hours are identical across countries, and thus these variables are perfectly correlated across countries (see Col. 1). The dynamics of these variables corresponds, thus, to that predicted by the corresponding closed economy (Long-Plosser; see Sect. 2). E.g., like its closed-economy counterpart, the Dellas economy with bubbles predicts that consumption is more volatile than output. ${ }^{27}$ Because of the predicted perfect correlation of Home and Foreign output, the terms of trade and the real exchange rate are constant, when there are just bubble shocks.

The no-bubble Dellas model with TFP shocks generates realistic output and consumption variability (see Col. 3, Table 3). However, investment, hours worked and the real exchange rate are less volatile than in the data (without bubbles, the Dellas model predicts that hours are constant). The no-bubble model with TFP shocks generates fluctuations in output, consumption and investment that are positively correlated across countries. The predicted cross-country correlation of output $(0.39)$ is smaller than the empirical correlation $(0.53)$, while predicted cross-country correlations of consumption and investment (0.56) are higher than the corresponding empirical correlations (about 0.4 ). Note that all model variants predict a zero trade balance. The bubble economy with joint bubble shocks and TFP shocks (Col. 2) generates higher cross-country correlations of output, consumption and investment than the no-bubble economy (Col. 3). Also, the presence of TFP shocks implies that the real exchange rate shows non-

26 The numerical simulations assume a discrete distribution of TFP innovations: $\varepsilon_{H, t+1}^{\theta}=a \cdot v_{H, t+1}+b \cdot v_{F, t+1}$ and $\varepsilon_{F, t+1}^{\theta}=b \cdot v_{H, t+1}+a \cdot v_{F, t+1}$ where $v_{H, t+1}$ and $v_{F, t+1}$ are independent random variables that equal 1 or -1 with probability 0.5 . I set $a=0.8447 \%, b=0.1108 \%$ to match the stated standard deviation and correlation of $\varepsilon_{H, t+1}^{\theta}, \varepsilon_{F, t+1}^{\theta}$.

27 The version of the Dellas economy considered in Table 3 assumes endogenous labor. Hours worked rise in response to a positive bubble shock. This explains why real activity is more volatile than in the closed economy (Long-Plosser) model with fixed labor considered in Section 2. 
negligible fluctuations (while the real exchange rate is constant in the bubble model with constant TFP, as discussed above).

\subsection{Financial autarky}

Country-specific bubbles can arise when there are impediments to international capital flows. Consider, e.g., a variant of the Dellas economy with financial autarky, so that net exports are constrained to be zero (balanced trade). Then the budget constraint of the country $i$ household is

$$
p_{i, t} Y_{i, t}=P_{i, t}\left(C_{i, t}+K_{i, t+1}\right) \text {, }
$$

i.e. the value of the country's intermediate good output equals the value of absorption (consumption plus investment spending). Under financial autarky, we thus have (from (47)):

$$
g_{i, t}=1+\kappa_{i, t} .
$$

Substituting (47) into the market clearing conditions (26) for Home and Foreign intermediate goods gives: $p_{i, t} Y_{i, t}=\xi \cdot p_{i, t} Y_{i, t}+(1-\xi) \cdot p_{j, t} Y_{j, t}, i \neq j$. Thus, $p_{i, t} Y_{i, t}=p_{j, t} Y_{j, t}$ holds again (as under complete markets). The labor supply condition (28) and the Euler equation (29) too continue to hold under financial autarky, and hence (33) and (34) remain valid:

$$
L_{i, t} /\left(1-L_{i, t}\right)=((1-\alpha) / \Psi) \cdot g_{i, t} \text { and } \alpha \beta E_{t} g_{i, t+1}=\kappa_{i, t} \quad \text { for } i=H, F \text {. }
$$

Solving for labor hours, we find

$$
L_{i, t}=\left(1+\kappa_{i, t}\right) /\left\{1+\kappa_{i, t}+\Psi /(1-\alpha)\right\},
$$

while the Euler equation can be expressed as

$$
\alpha \beta E_{t}\left(1+\kappa_{i, t+1}\right)=\kappa_{i, t} .
$$

Under financial autarky, $\kappa_{H, t} \neq \kappa_{F, t}$ is possible. Local bubbles induce country-specific fluctuations in hours worked (see (49)). (47) implies $C_{i, t}=\left(1 /\left(1+\kappa_{i, t}\right)\right)\left(p_{i, t} / P_{i, t}\right) Y_{i, t}$. As $p_{i, t} / P_{i, t}=\left(p_{i, t} / p_{j, t}\right)^{1-\xi}=\left(Y_{j, t} / Y_{i, t}\right)^{1-\xi}($ for $j \neq i)$ we obtain

$$
C_{i, t}=\left(1 /\left(1+\kappa_{i, t}\right)\right)\left(Y_{i, t}\right)^{\xi}\left(Y_{j, t}\right)^{1-\xi} \text { and } K_{i, t+1}=\left(\kappa_{i, t} /\left(1+\kappa_{i, t}\right)\right)\left(Y_{i, t}\right)^{\xi}\left(Y_{j, t}\right)^{1-\xi} \text {. }
$$

Note that $C_{H, t} / C_{F, t}=\left(\left(1+\kappa_{F, t}\right) /\left(1+\kappa_{H, t}\right)\right) P_{F, t} / P_{H, t}$. Thus,

$$
P_{H, t} C_{H, t}=\left(\left(1+\kappa_{F, t}\right) /\left(1+\kappa_{H, t}\right)\right) P_{F, t} C_{F, t} .
$$

Local bubbles, under financial autarky, thus violate the international risk sharing condition. 


\section{Rational bubbles in a two-country $\mathrm{RBC}$ model with incomplete capital depreciation (no TVC)}

This Section discusses rational bubbles in a more general two-country RBC model that resembles the classic International RBC model proposed by Backus et al. (1994). This model cannot be solved in closed form. It assumes incomplete capital depreciation, a CES final good aggregator, and it allows for non-unitary risk aversion. Other model features are identical to those of the Dellas model. Thus, each country is specialized in the production of a distinct tradable good. Domestic and imported tradables are combined into a non-tradable final good used for consumption and investment. Complete global financial markets are assumed. The law of motion of Home and Foreign TFP is again given by (46).

As in the closed economy RBC model of Sect. 3, I assume the period utility function $U\left(C_{i, t}, L_{t}\right)=\ln \left(C_{i, t}-\bar{C}\right)+\Psi \cdot \ln \left(1-L_{i, t}\right)$, with $\bar{C} \geq 0$. The country $i$ final good is generated by combining domestic and imported intermediate goods using a CES aggregator: $Z_{i, t}=\left[\xi^{1 / \phi} \cdot\left(y_{i, t}^{i}\right)^{(\phi-1) / \phi}+(1-\xi)^{1 / \phi} \cdot\left(y_{i, t}^{j}\right)^{(\phi-1) \phi}\right]^{\phi(\phi-1)}, \quad j \neq i, \quad$ where $\phi$ is the substitution elasticity between domestic and imported intermediates. There is local bias in final good production, $\frac{1}{2}<\xi<1$. The price of country $i$ 's final good $\left(P_{i, t}\right)$ now is $P_{i, t}=\left[\xi \cdot\left(p_{i, t}\right)^{1-\phi}+(1-\xi) \cdot\left(p_{j, t}\right)^{1-\phi}\right]^{1 /(1-\phi)}, j \neq i$, while country $i$ 's demand functions for domestic and imported inputs are $y_{i, t}^{i}=\xi \cdot\left(p_{i, t} / P_{i, t}\right)^{-\phi} Z_{i, t}$ and $y_{i, t}^{j}=(1-\xi) \cdot\left(p_{j, t} / P_{i, t}\right)^{-\phi} Z_{i, t}$, respectively. The law of motion of country $i$ 's capital stock is $K_{i, t+1}=(1-\delta) K_{i, t}+I_{i, t}$, where $0<\delta<1$ is the capital depreciation rate. The final good market clearing condition in country $i$ is $Z_{i, t}=C_{i, t}+I_{i, t}$.

The static equilibrium conditions (i.e. market clearing conditions and labor supply equations) allow to solve for date $t$ consumption, hours worked and terms of trade $C_{i, t}, L_{i, t}, q_{i, t}$ as functions of both countries' capital stocks in $t$ and $t+1$ and of date $t$ productivity, $K_{j, t}, K_{j, t+1}, \theta_{j, t}$ for $j=H, F$. By substituting these functions into the two countries' capital Euler equations, one can write these Euler equations as expectational difference equations in Home and Foreign capital:

$$
E_{t} H_{i}\left(\overrightarrow{K_{t+2}}, \overrightarrow{K_{t+1}}, \overrightarrow{K_{t}}, \overrightarrow{\theta_{t+1}}, \overrightarrow{\theta_{t}}\right)=1 \text { for } i=H, F,
$$


where $\overrightarrow{K_{t}} \equiv\left(K_{H, t}, K_{F, t}\right)$ and $\vec{\theta}_{t} \equiv\left(\theta_{H, t}, \theta_{F, t}\right)$ are vectors of Home and Foreign capital and TFP, respectively. The function $H_{i}$ maps $R_{+}^{10}$ into $R$.

The no-bubble solution of the model (that obtains when TVCs are imposed) is described by decision rules $K_{i, t+1}=\lambda_{i}\left(\vec{K}_{t}, \vec{\theta}_{t}\right)$ that map date $t$ capital and TFP into capital at date $t+1$.

Assume that there is no transversality condition (TVC) for capital, which makes rational bubbles possible. I consider a bubble process that parallels the bubbles discussed in previous Sections. Assume that capital $K_{i, t+1}$ takes two possible values: $K_{i, t+1} \in\left\{K_{i, t+1}^{L}, K_{i, t+1}^{H}\right\}$, where $K_{i, t+1}^{L}=\lambda_{i}\left(\vec{K}_{t}, \vec{\theta}_{t}\right) \cdot e^{\Delta}$, with $\Delta>0$. Like in previous models, $\Delta>0$ is required to generate recurrent bubbles. As in the Dellas economy with complete financial markets, the bubble has to be perfectly synchronized across countries. A bubble-driven investment boom occurs in country $H$ if and only if a boom occurs simultaneously in country $F$. Thus, $K_{H, t+1}^{H}$ and $K_{F, t+1}^{H}$ are realized together (and so are $K_{H, t+1}^{L}$ and $K_{F, t+1}^{L}$ ). Note that the superscripts 'H' (boom) and 'L' (bust) refer to the state of the bubble, while the subscripts ' $\mathrm{H}$ ' (Home) and ' $\mathrm{F}$ ' (Foreign) refer to the country.

Consider a world economy that starts at date $t=0$, with exogenous initial capital stocks $K_{H, 0}, K_{F, 0}$. Let $u_{t} \in\{0 ; 1\}$ be an exogenous i.i.d. sunspot that takes values 0 and 1 with probabilities $\pi$ and $1-\pi$, respectively, where $0<\pi<1$. Assume that the sunspot is independent of TFP. Then the following process for Home and Foreign capital stocks $\left\{K_{H, t} K_{F, t}\right\}_{t \geq 0}$ is a recurrent rational bubble:

(a) $K_{i, t+2}=K_{i, t+2}^{L}=\lambda_{i}\left(\overrightarrow{K_{t+1}}, \overrightarrow{\theta_{t+1}}\right) \cdot e^{\Delta}$ for $i=H, F$ if $u_{t+1}=0$, for $t \geq 0$;

(b) $K_{i, t+2}=K_{i, t+2}^{H}$ for $i=H, F$, if $u_{t+1}=1$, for $t \geq 0$, where $K_{H, t+2}^{H}, K_{F, t+2}^{H}$ satisfy the Home and Foreign date $t$ Euler equations (53).

$K_{i, 1}$ (for $i=H, F$ ), i.e. the two countries' capital stocks set in period 0 , do not obey the recursion that governs the capital stocks in subsequent periods. Thus, $K_{i, 1}$ is indeterminate. In the numerical simulations, I set $K_{i, 1}=\lambda_{i}\left(\overrightarrow{K_{0}}, \overrightarrow{\theta_{0}}\right) \cdot e^{\Delta}$ for $i=\mathrm{H}, \mathrm{F}$. Following the specification in Sect. 3, I focus on equilibria in which, conditional on date $t$ information, productivity innovations at $t+1$ have equiproportional effects on country $i$ 's boom and bust capital stocks $K_{i, t+2}^{H} K_{i, t+2}^{L}$. Thus: 
$K_{i, t+2}^{H}=s_{i, t}^{H} \cdot K_{i, t+2}^{L}$ for $i=H, F$, where $s_{i, t}^{H}>0$ is in the date $t$ information set. This assumption greatly simplifies the computation of bubble equilibria. Substituting the formulae for $K_{i, t+2}^{L}$ and $K_{i, t+2}^{H}$ into the Euler equation (53) gives:

$$
\begin{gathered}
\pi E_{t} H_{i}\left(\left(\lambda_{H}\left(\overrightarrow{K_{t+1}}, \overrightarrow{\theta_{t+1}}\right) e^{\Delta}, \lambda_{F}\left(\overrightarrow{K_{t+1}}, \overrightarrow{\theta_{t+1}}\right) e^{\Delta}\right), \overrightarrow{K_{t+1}}, \overrightarrow{K_{t}}, \overrightarrow{\theta_{t+1}}, \overrightarrow{\theta_{t}}\right)+ \\
(1-\pi) E_{t} H_{i}\left(\left(s_{H, t}^{H} \cdot \lambda_{H}\left(\overrightarrow{K_{t+1}}, \overrightarrow{\theta_{t+1}}\right) e^{\Delta}, S_{F, t}^{H} \cdot \lambda_{F}\left(\overrightarrow{K_{t+1}}, \overrightarrow{\theta_{t+1}}\right) e^{\Delta}\right), \overrightarrow{K_{t+1}}, \overrightarrow{K_{t}}, \overrightarrow{\theta_{t+1}}, \overrightarrow{\theta_{t}}\right)=1 \text { for } i=H, F .
\end{gathered}
$$

Given $K_{H, t+1}, K_{F, t+1}$, the date $t$ Euler equations of both countries only feature two unknown endogenous variables in period $t: s_{H, t}^{H}$ and $s_{F, t}^{H}$. Computing a bubble equilibrium requires solving the Home and Foreign Euler equations (54) for $s_{H, t}^{H}, s_{F, t}^{H}$, at each date $t$. Once $s_{H, t}^{H}, s_{F, t}^{H}$ have been determined, the process of capital is fully specified, and consumption, hours, output etc. can be solved for using the static equilibrium conditions.

\subsection{Quantitative results}

As in Sect. 3, I set $\alpha=1 / 3, \beta=0.99, \delta=0.025$. $\Psi$ (utility weight on leisure) is again set so that the Frisch labor supply elasticity is unity, at the steady state. As in the calibration of the Dellas model, the local spending bias parameter is set at $\xi=0.9$. The substitution elasticity between domestic and imported intermediates is set at $\phi=1.5$; that value is consistent with estimated price elasticities of aggregate trade flows and it has been widely used in International RBC models (e.g., Backus et al. (1994)). The parameters of the bubble process are the same as in the closed economy model (with incomplete capital depreciation) studied in Sect. 3. Thus, $\Delta$ is again set at $\Delta=10^{-6}$. I consider two values of the bust probability: $\pi=0.2$ and $\pi=0.5$.

Predicted business cycle statistics generated by the two-country RBC model with incomplete capital depreciation are shown in Table 4. Cols. labelled 'Unit Risk Aversion' (or 'Unit RA') assume log utility (minimum consumption set at $\bar{C}=0$ ). In Cols. labelled 'High RA', $\bar{C}$ is set at 0.8 times steady state consumption (implied risk aversion, at steady state: 5 ).

Cols. (9) and (10) of Table 4 show simulated business cycle statistics for versions of the no-bubble model (TVC imposed) driven by TFP shocks. The simulations confirm findings that are well known from the International RBC literature (e.g., Backus et al. (1994), Kollmann (1996)): a complete markets no-bubble model driven by TFP shocks can capture the historical 
volatility of output and investment, but it underpredicts the empirical volatility of the real exchange rate. The no-bubble model here reproduces the fact that net exports are countercyclical. However, the model-predicted cross-country correlations of output and investment are markedly lower than the corresponding historical correlations. By contrast, the model predicts that consumption is highly correlated across countries. The low predicted cross-country correlation of output reflects the fact that, with complete financial markets, a positive shock to Home productivity raises Foreign consumption, which reduces Foreign labor supply, and thus lowers Foreign output, on impact (while Home output increases). ${ }^{28}$

Simulated business cycle statistics for the bubble economy with just bubble shocks (constant TFP) are reported in Cols. (1)-(4) of Table 4. Standard deviations, correlations with domestic GDP, autocorrelations and mean values are identical to the corresponding statistics for the closed economy bubble model (with incomplete capital depreciation) studied in Sect. 3 (see Cols. (1)-(4) of Table 2). This is due to the fact that, in the two-country model with complete markets, bubbles are perfectly correlated across countries; with just bubble shocks, real activity is thus perfectly correlated across countries, the terms of trade are constant and net exports are zero. Predicted volatility of output and consumption induced by bubble shocks (Cols. (1)-(4) of Table 2) is roughly comparable to volatility in the no-bubble model with TFP shocks (Cols. (9),(10)), but the volatility of hours worked is higher in the bubble economy.

Predicted business cycle statistics for the bubble economy, with simultaneous bubble shocks and TFP shocks, are shown in Cols. (5)-(8) of Table 4. With joint bubble shocks and TFP shocks, the predicted volatility of real activity is higher, and thus generally closer to the data, than the volatility generated by the no-bubble model with TFP shocks. The model with joint bubble and TFP shocks is especially successful at matching the positive empirical cross-country correlations of output and investment, and the counter-cyclicality of the trade balance; however the predicted cross-country consumption correlation is too high, when compared to the data.

Fig. 4 shows simulated sample paths for the model version with 'High Risk Aversion' and a bust probability $\pi=0.2$. Panels (1) and (2) of the Figure show results for the bubble economy with just bubble shocks, and for the bubble economy with joint bubble and TFP shocks, respectively. Panel (3) of Fig. 4 pertains to a no-bubble economy with TFP shocks; in

\footnotetext{
${ }^{28}$ The no-bubbles variant of the Dellas model driven by TFP shocks generates higher cross-country output correlations (see Col. (3) of Table 3) because, in that variant, hours worked are constant.
} 
that variant, the negative cross-country correlation of high-frequency output and investment fluctuations is clearly discernible. Bubble shocks induce relatively widely spaced output and investment booms that are perfectly correlated across countries (see Panel (1)). In the bubble economy with joint bubble and TFP shocks, output and investment are markedly more synchronized across countries than in the no-bubble economy (with TFP shocks); see Panel (2) of Fig. 4.

\section{Conclusion}

This paper constructs bounded rational bubbles in non-linear DSGE models of the macroeconomy. The notion of a 'rational bubble' refers to multiple equilibria due to the absence of a transversality condition (TVC) for capital. The lack of TVC can be justified by assuming an OLG population structure with finitely-lived agents. Bounded rational bubbles provide a novel perspective on the drivers and mechanisms of business cycles. This paper studies bubble equilibria in which the economy undergoes boom-bust cycles characterized by persistent investment and output expansions which are followed by abrupt contractions in real activity. Importantly, the existence of multiple stable bubble equilibria is due to non-linear effects. Linearized versions of the models considered here have a unique stable solution. In contrast to explosive rational bubbles in linear models (Blanchard (1979)), the rational bubbles in non-linear models considered here are bounded. Applications to both closed and open economies are analyzed. It is shown that rational bubbles in non-linear models can generate persistent fluctuations of real activity and capture key business cycle stylized facts. In a two-country model with integrated financial markets, rational bubbles must be perfectly correlated across countries. Global bubbles may, thus, help to explain the synchronization of international business cycles. 


\section{References}

Abel, Andrew, Gregory Mankiw, Lawrence Summers and Richard Zeckhauser, 1989. Assessing Dynamic Efficiency: Theory and Evidence. Review of Economic Studies 56, 1-20. https://doi.org/10.2307/2297746

Ascari, Guido, Paolo Bonomolo and Hedibert Lopes, 2019. Walk on the Wild Side: Temporarily Unstable Paths and Multiplicative Sunspots. American Economic Review 109, 1805-1842. https://doi.org/10.1257/aer.20160576

Bacchetta, Philippe, Cédric Tille and Eric van Wincoop, 2012. Self-Fulfilling Risk Panics. American Economic Review 102, 3674-3700. https://doi.org/10.1257/aer.102.7.3674

Backus, David, and Gregor Smith, 1993. Consumption and Real Exchange Rates in Dynamic Economies with Non-traded Goods. Journal of International Economics 35, 297-316. https://doi.org/10.1016/0022-1996(93)90021-o

Backus, David, Patrick Kehoe, and Finn Kydland, 1994. Dynamics of the Trade Balance and the Terms of Trade: The J-Curve? American Economic Review 84, 84-103.

Benhabib, Jess and Roger Farmer, 1999. Indeterminacy and Sunspots in Macroeconomics. In: Handbook of Macroeconomics (J. Taylor and M. Woodford, eds.), Elsevier, Vol. 1A, 387448. https://doi.org/10.1016/s1574-0048(99)01009-5

Blanchard, Olivier, 1979. Speculative Bubbles, Crashes and Rational Expectations. Economics Letters 3, 387-398. https://doi.org/10.1016/0165-1765(79)90017-x

Blanchard, Olivier and Charles Kahn, 1980. The Solution of Linear Difference Models under Rational Expectations. Econometrica 48, 1305-1311. https://doi.org/10.2307/1912186

Blanchard, Olivier and Mark Watson, 1982. Bubbles, Rational Expectations and Financial Markets. NBER Working Paper 945. https://doi.org/10.3386/w0945

Blanchard, Olivier and Stanley Fischer, 1989. Lectures on Macroeconomics. Cambridge, MA: MIT Press.

Coeurdacier, Nicolas, Robert Kollmann and Philippe Martin, 2010. International Portfolios, Capital Accumulation and Foreign Assets Dynamics. Journal of International Economics 80, 100-112. https://doi.org/10.1016/j.jinteco.2009.05.006

Dellas, Harris, 1986. A Real Model of the World Business Cycle. Journal of International Money and Finance 5, 381-294. https://doi.org/10.1016/0261-5606(86)90036-7

Galí, Jordi, 2018. Monetary Policy and Bubbles in a New Keynesian Model with Overlapping Generations. Working Paper, CREI.

Holden, Tom, 2016a. Existence and Uniqueness of Solutions to Dynamic Models with Occasionally Binding Constraints. Working Paper, University of Surrey.

Holden, Tom, 2016b. Computation of Solutions to Dynamic Models with Occasionally Binding Constraints. Working Paper, University of Surrey.

Judd, Kenneth, 1998. Numerical Methods in Economics. Cambridge, MA: MIT Press.

King, Robert and Sergio Rebelo, 1999. Resuscitating Real Business Cycles. In: Handbook of

Macroeconomics (J. Taylor and M. Woodford, eds.), Elsevier, Vol. 1B, 927-1007. https://doi.org/10.1016/s1574-0048(99)10022-3 
Kollmann, Robert, 1991. Essays on International Business Cycles. PhD Dissertation, Economics Department, University of Chicago.

Kollmann, Robert, 1995. Consumption, Real Exchange Rates and the Structure of International Asset Markets. Journal of International Money and Finance 14, 191-211. https://doi.org/10.1016/0261-5606(94)00011-o

Kollmann, Robert, 1996. Incomplete Asset markets and the Cross-Country Consumption Correlation Puzzle. Journal of Economic Dynamics \& Control 20, 945-962. https://doi.org/10.1016/0165-1889(95)00883-7

Kollmann, Robert, Serguei Maliar, Benjamin Malin and Paul Pichler, 2011a. Comparison of Numerical Solutions to a Suite of Multi-Country Models. Journal of Economic Dynamics and Control 35, pp.186-202. https://doi.org/10.1016/j.jedc.2010.09.013

Kollmann, Robert, Jinill Kim and Sunghyun Kim, 2011b. Solving the Multi-Country Real Business Cycle Model Using a Perturbation Method. Journal of Economic Dynamics and Control 35, 203-206. https://doi.org/10.1016/j.jedc.2010.09.012

Long, John and Charles Plosser, 1983. Real Business Cycles. Journal of Political Economy 91, 39-69. https://doi.org/10.1086/261128

Mussa, Michael, 1990. Exchange Rates in Theory and Reality. Essays in International Finance No. 179, Princeton University.

Martin, Alberto and Jaume Ventura, 2018. The Macroeconomics of Rational Bubbles: A User's Guide. Annual Review of Economics 10, 505-539.

https://doi.org/10.1146/annurev-economics-080217-053534

Schmitt-Grohé, Stephanie, 1997. Comparing Four Models of Aggregate Fluctuations Due to Self-Fulfilling Expectations. Journal of Economic Theory 72, 96-47. https://doi.org/10.1006/jeth.1996.2195

Schmitt-Grohé, Stephanie and Martin Uribe, 2004. Solving Dynamic General Equilibrium Models Using a Second-Order Approximation to the Policy Function. Journal of Economic Dynamics and Control 28, 755 - 775. https://doi.org/10.1016/s0165-1889(03)00043-5

Stracca, Livio, 2004. Behavioral Finance and Asset Prices: Where Do We Stand? Journal of Economic Psychology 25, 373-405. https://doi.org/10.1016/s0167-4870(03)00055-2

Taylor, John, 1977. Conditions for Unique Solutions in Stochastic Macroeconomic Models with Rational Expectations. Econometrica 45, 1377-1385. https://doi.org/10.2307/1912306

Woodford, Michael, 1986. Stationary Sunspot Equilibria: The Case of Small Fluctuations Around a Deterministic Steady State'. Working Paper, University of Chicago. 
Appendix A: An OLG model with finitely-lived agents that has the same aggregate resource constraint and the same aggregate Euler equation as a Long-Plosser economy inhabited by an infinitely-lived representative agent

The key contribution of this paper is to construct bounded bubbles in non-linear DSGE models without transversality condition (TVC). Explosive bubbles in linear models (Blanchard (1979)) are likewise predicated on the absence of a TVC. The lack of TVC can be justified by the assumption that the economy has an overlapping generations (OLG) population structure with finitely-lived households. This Appendix presents a novel OLG structure with finitely-lived agents that has the same aggregate static equations and the same aggregate Euler equation as a Long-Plosser economy inhabited by an infinitely-lived representative agent. Thus equations (1)(4) continue to hold in the OLG structure. Importantly, there is no TVC in the OLG structure, due to agents' finite planning horizon. The OLG structure provides thus a motivation for exploring rational bubbles (i.e. multiple equilibria due to the lack of TVC) in the Long-Plosser economy, and in other DSGE models.

Two key features of the OLG structure considered here are: ${ }^{29}$ (I) complete risk sharing between contemporaneous generations. (II) Newborn agents receive a wealth endowment such that consumption by newborns represents a time-invariant share of aggregate consumption; under log utility, this requires that the wealth endowments of newborns is a time-invariant fraction of aggregate wealth.

\section{OLG version of a Long-Plosser economy}

Following the Long-Plosser model discussed in Sect. 2, this Appendix assumes a closed economy with log utility, a Cobb-Douglas production function and full capital depreciation. Labor hours are constant and normalized at unity. Generalization to CRRA utility and to the 'High Risk Aversion' specification of Sect. 3.1 (in which consumption utility is given by $\ln \left(C_{t}-\bar{C}\right)$, with $\left.\bar{C}>0\right)$ is straightforward. The logic also goes through under incomplete capital depreciation and variable labor, and in a multi-country model.

Assume that a measure 1 of agents is born each period. All agents live $\mathrm{N}<\infty$ periods. Thus, at each date, a fraction $1 / \mathrm{N}$ of the population is in the $i$-th period of their life, $i=1, \ldots, \mathrm{N}$. All members of the same age cohort are identical. All agents have time-additive (log) utility and the

\footnotetext{
${ }^{29}$ Assumption (I) is also used by Gali (2018). Assumption (II) is novel (to the best of my knowledge).
} 
same subjective discount factor, $\beta$. Let $c_{i, t}$ denote the consumption of agents who are in the $i$-th period of their life at date $t$. I refer to these agents as 'generation $i$ ' in period $t$. Generation $\mathrm{i}$ at date $t$ becomes generation $i+1$ at $t+1($ for $1 \leq i<\mathrm{N}$ ). The expected life-time utility of the generation born at date $t$ is $E_{t} \sum_{s=1}^{N} \beta^{s-1} \ln \left(c_{s, t+s-1}\right)$. Aggregate consumption at date $t$ is $C_{t}=\sum_{i=1}^{N} c_{i, t}$.

Assume that the aggregate technology of the economy and the aggregate resource constraint of the OLG economy are the same as in the Long-Plosser model described in Sect. 2. Thus, aggregate output is $Y_{t}=\theta_{t}\left(K_{t}\right)^{\alpha}$, with $K_{t}=\sum_{i=1}^{N} K_{i, t}$ is aggregate capital, where $K_{i, t}$ is the capital stock owned by generation $i$. The aggregate resource constraint is $Y_{t}=C_{t}+I_{t}$. Because of full capital depreciation, the law of motion of the aggregate capital stock is $K_{t+1}=I_{t}$, where $I_{t}$ denotes aggregate (gross) investment.

Assume that at each date $t$ a complete set of one-period claims with state-continent date $t+1$ payouts is traded. This implies that, in equilibrium, the individual consumption growth rate between $t$ and $t+1$ is equated across all agents who are alive in both periods (efficient risk sharing):

$$
c_{i+1, t+1} / c_{i, t}=c_{2, t+1} / c_{1, t} \text { for } i=2, . ., \mathrm{N}-1 .
$$

Let $\lambda_{i, t} \equiv c_{i, t} / C_{t}$ denote the ratio of generation $i$ 's consumption divided by aggregate consumption at $t$. I refer to $\lambda_{i, t}$ as the 'consumption share' of generation $i$, in period $t$. (A.1) implies

$$
\lambda_{i+1, t+1} / \lambda_{i, t}=\lambda_{2, t+1} / \lambda_{1, t} \text { for } \mathrm{i}=2, . ., \mathrm{N}-1 .
$$

(A.2) and the adding up constraint

$$
\sum_{i=1}^{N} \lambda_{i, t+1}=1
$$

provide a system of $\mathrm{N}-1$ equations in the $\mathrm{N}$ consumption shares at date $t+1: \lambda_{1, t+1}, \lambda_{2, t+1}, \ldots, \lambda_{N, t+1}$. Assume, henceforth, that the consumption share of newborn agents, during the first period of their life, is time-invariant: $\lambda_{1, t}=\lambda_{1} \forall t$. (A constant newborn consumption share can be sustained by allocating to newborns a time-invariant share of aggregate wealth; see below.) Then we can use (A.2) and (A.3) to solve for the date $t+1$ consumption shares $\left\{\lambda_{i, t+1}\right\}_{i=1, \ldots, N}$ for given values of the date $\mathrm{t}$ shares $\left\{\lambda_{i, t}\right\}_{i=1, \ldots, N}$ : 


$$
\lambda_{i+1, t+1}=\left(1-\lambda_{1}\right) \lambda_{i, t} /\left(1-\lambda_{N, t}\right) \text { for } \mathrm{i}=1, . ., \mathrm{N}-1 .
$$

(A.4) defines a system of difference equations in consumption shares. Given a time-invariant generation 1 consumption share $\lambda_{1}$, the consumption shares of generation $i=2, . ., \mathrm{N}$ converges asymptotically to a constant consumption share $\lambda_{i}$ (numerical experiments show that convergence to steady state shares is fast). The $\mathrm{N}$ steady state consumption shares obey

$$
\lambda_{i+1}=\left(1-\lambda_{1}\right) \lambda_{i} /\left(1-\lambda_{N}\right) \text { for } \mathrm{i}=1, . ., \mathrm{N}-1 .
$$

Given $\lambda_{1}$, these equations pin down unique consumption shares of generations $i=2, . ., \mathrm{N}$ that are consistent with the adding up constraint $\sum_{i=1}^{N} \lambda_{i}=1$. The following discussion assumes that all generations' consumption shares equal their steady state values, so that all consumption shares are time-invariant: $\lambda_{i, t}=\lambda_{i} \forall t, \forall i=1, . ., N$.

The date $t$ capital Euler equations of generation $i=1, . ., \mathrm{N}-1$ is $E_{t} \rho_{t, t+1} r_{K, t+1}=1$, where $r_{K, t+1}$ is the gross rate of return (between $t$ and $t+1$ ) on capital, while $\rho_{t, t+1}=\beta c_{i, t} / c_{i+1, t+1}$ is the common intertemporal marginal rate of substitution (IMRS) between $t$ and $t+1$ of these generations. (Full risk sharing implies that the IMRS is equated across contemporaneous generations; see (A.1)). Note that

$$
\rho_{t, t+1}=\beta \sum_{i=1}^{N-1} c_{i, t} / \sum_{i=2}^{N} c_{i, t+1}=\beta\left(C_{t}-c_{N, t}\right) /\left(C_{t+1}-c_{1, t+1}\right)=\beta\left[\left(1-\lambda_{N}\right) /\left(1-\lambda_{1}\right)\right] \cdot C_{t} / C_{t+1} \cdot
$$

The Euler equation can thus be expressed as

$$
E_{t} \widetilde{\beta} C_{t} / C_{t+1} r_{K, t+1}=1 \text {, with } \widetilde{\beta} \equiv \beta \times\left(1-\lambda_{N}\right) /\left(1-\lambda_{1}\right) .
$$

We hence see that, up to a rescaling of the subjective discount factor when $\lambda_{1} \neq \lambda_{N}$, this OLG model implies an 'aggregate' Euler equation (in terms of aggregate consumption) that has the same form as the Euler equation in an economy with an infinitely-lived representative household. If the initial wealth endowment of newborns is such that $\lambda_{1}=1 / N$, then $\lambda_{i}=1 / N$ holds for $i=1, . ., \mathrm{N}$, which implies $\widetilde{\beta} \equiv \beta$. In the special case where $\lambda_{1}=1 / N$, the aggregate Euler equation of the OLG economy is thus identical to the Euler of an infinitely-lived representative household. However, the TVC of an infinitely-lived household's decision problem, $\lim _{\tau \rightarrow \infty} \beta^{\tau} E_{t} u^{\prime}\left(C_{t+\tau}\right) K_{t+\tau+1}=0$, does not hold in the OLG structure, due to agents' finite horizon. 


\section{Wealth shares}

Under log utility, a time-invariant consumption share $\lambda_{1}$ of the new-born cohort is sustained by allocating to each newborn generation a time-invariant share of the aggregate wealth of all cohorts. To see this, let $\omega_{i, t}$ denote the wealth of generation $i=1, \ldots, \mathrm{N}$ in period $t . \omega_{i, t}$ equals the present value of generation $i$ 's consumption stream: $\omega_{i, t}=E_{t} \sum_{s=0}^{N-i} \rho_{t, t+s} c_{i+s, t+s}$, where $\rho_{t, t}=1$ while the stochastic discount factor $\rho_{t, t+s}$ is a product of the one-period-ahead discount factors defined above: $\rho_{t, t+s}=\prod_{\tau=0}^{\tau=s-1} \rho_{t+\tau, t+\tau+1}$ for $s \geq 1$. Under efficient risk sharing across contemporaneous generations (see (A.1)), $\rho_{t, t+s}=\beta^{s} c_{i, t} / c_{i+s, t+s}$ holds for $0<s \leq N-i$. Thus $\omega_{i, t}=c_{i, t} \sum_{s=0}^{N-i} \beta^{s}$ and hence

$$
c_{i, t}=\phi_{i} \cdot \omega_{i, t}, \text { with } \phi_{i} \equiv(1-\beta) /\left(1-\beta^{N-i+1}\right) \quad \text { for } \mathrm{i}=1, . ., \mathrm{N} \text {. }
$$

Thus, in each period, generation $i$ consumes a fraction $\phi_{i}$ of her wealth. $\phi_{i}$ is generationspecific, but time invariant. In an equilibrium with time-invariant generational consumption shares, the period $t$ wealth of generation $i$ equals thus $\omega_{i, t}=\left(\lambda_{i} / \phi_{i}\right) C_{t}$. The wealth share of generation $i$ is hence:

$$
\omega_{i, t} / \sum_{s=1}^{N} \omega_{s, t}=\left(\lambda_{i} / \phi_{i}\right) / \sum_{s=1}^{N}\left(\lambda_{s} / \phi_{s}\right) \equiv \kappa_{i}
$$

Note that this wealth share is time-invariant. Thus, an equilibrium with time-invariant generational consumption shares exhibits time-invariant generational wealth shares. As pointed out above, the consumption share of newborn generations, $\lambda_{1}$, pins down the (steady state) consumption shares of older generations, i.e. $\lambda_{i}$ is a function of $\lambda_{1}: \lambda_{i}=\Lambda_{i}\left(\lambda_{1}\right)$ for $i=2, . ., \mathrm{N}$. There is, hence, a unique mapping from $\lambda_{1}$ to the wealth shares of each generation (see (A.5) for the definition of $\left.\kappa_{i}\right)$ :

$$
\kappa_{i}=\mathrm{K}_{i}\left(\lambda_{1}\right)=\left(\Lambda_{i}\left(\lambda_{1}\right) / \phi_{i}\right) / \sum_{s=1}^{N}\left(\Lambda_{s}\left(\lambda_{1}\right) / \phi_{s}\right)
$$

If the new-born generation is allocated a wealth share $\kappa_{1}=\left(\lambda_{1} / \phi_{1}\right) / \sum_{s=1}^{N}\left(\Lambda_{s}\left(\lambda_{1}\right) / \phi_{s}\right)$, then this sustains an equilibrium in which the consumption share of the new-born generation is $\lambda_{1}$ A consumption allocation in which all generations have an identical consumption share $\lambda_{i}=1 / N$ is 
sustained by allocating to the newborn generation a wealth share $\kappa_{1}=\left(1 / \phi_{1}\right) / \sum_{s=1}^{N} 1 / \phi_{s}$. As an example, assume that life lasts 80 years, i.e. $\mathrm{N}=320$ quarters, and that the quarterly subjective discount factor is $\beta=0.99$; then the consumption allocation with equal consumption shares $\lambda_{i}=1 / N=0.3125 \%$ requires a newborn wealth share of $\kappa_{1}=0.4267 \%$.

\section{Appendix B: Solving for rational bubble equilibria in the closed economy $R B C$ model with incomplete capital depreciation (Sect. 3)}

This Appendix describes the numerical method that is used to solve the model developed in Sect.

3. The static equilibrium conditions (11) and (12) allow to express date $t$ consumption and hours worked as functions of capital stocks at $t$ and $t+1$ and of TFP: $C_{t}=\gamma\left(K_{t+1}, K_{t}, \theta_{t}\right)$ and $L_{t}=\eta\left(K_{t+1}, K_{t}, \theta_{t}\right)$. Note that the labor supply equation (12) can be written as

$$
C_{t}=[(1-\alpha) / \Psi] \cdot \theta_{t}\left(K_{t}\right)^{\alpha}\left(L_{t}\right)^{-\alpha}\left(1-L_{t}\right) .
$$

Substituting this expression into the resource constraint (11) gives:

$$
[(1-\alpha) / \Psi] \cdot \theta_{t}\left(K_{t}\right)^{\alpha}\left(L_{t}\right)^{-\alpha}\left(1-L_{t}\right)=\theta_{t}\left(K_{t}\right)^{\alpha}\left(L_{t}\right)^{1-\alpha}+(1-\delta) K_{t}-K_{t+1} .
$$

Equivalently: $1=A_{1, t} \cdot\left(L_{t}\right)^{\alpha}+A_{2} \cdot L_{t}$, with $\quad A_{1, t}=-\left[K_{t+1}-(1-\delta) K_{t}\right]\left\{[(1-\alpha) / \Psi] \cdot \theta_{t}\left(K_{t}\right)^{\alpha}\right\}, A_{2} \equiv[1+\Psi /(1-\alpha)]$.

For the assumed capital elasticity of output $\alpha=1 / 3$, this (cubic) equation has a unique closed form solution for date $t$ hours worked $L_{t}$ as a function of $K_{t+1}, K_{t}, \theta_{t}$. Substitution of the formula for hours into (B.1) gives a closed form formula for consumption $C_{t}$ as a function of $K_{t+1}, K_{t}, \theta_{t}$.

Substitution of the formulae for hours and consumption into the date $t$ Euler equation (13) gives: $E_{t} H\left(K_{t+2}, K_{t+1}, K_{t}, \theta_{t+1}, \theta_{t}\right)=1$, where

$$
H\left(K_{t+2}, K_{t+1}, K_{t}, \theta_{t+1}, \theta_{t}\right) \equiv \beta\left\{\gamma\left(K_{t+1}, K_{t}, \theta_{t}\right) / \gamma\left(K_{t+2}, K_{t+1}, \theta_{t+1}\right)\right\}\left(\alpha \theta_{t+1}\left(K_{t+1}\right)^{\alpha-1}\left(\eta\left(K_{t+2}, K_{t+1}, \theta_{t+1}\right)\right)^{1-\alpha}+1-\delta\right) .
$$

In the rational bubble equilibrium considered in Sect. 3, $K_{t+2} \in\left\{K_{t+2}^{L} ; K_{t+2}^{H}\right\}$ holds with probabilities $\pi$ and $1-\pi$, respectively. An exogenous sunspot determines whether $K_{t+2}^{L}$ or $K_{t+2}^{H}$ is realized. The sunspot is independent of TFP. The 'bust' capital stock $\left(K^{L}\right)$ is specified as $K_{t+2}^{L}=\lambda\left(K_{t+1}, \theta_{t+1}\right) e^{\Delta}, \Delta>0$, where $\lambda$ is the no-bubble decision rule (that holds under the TVC). The 'boom' capital stock $\left(K^{H}\right)$ is specified as $K_{t+2}^{H}=s_{t}^{H} K_{t+2}^{L}$, where $s_{t}^{H}>0$ is a household decision variable at date $t$. Thus, Euler equation can be written as 


$$
\pi E_{t} H\left(\lambda\left(K_{t+1}, \theta_{t+1}\right) e^{\Delta}, K_{t+1}, K_{t}, \theta_{t+1}, \theta_{t}\right)+(1-\pi) \cdot E_{t} H\left(s_{t}^{H} \cdot \lambda\left(K_{t+1}, \theta_{t+1}\right) e^{\Delta}, K_{t+1}, K_{t}, \theta_{t+1}, \theta_{t}\right)=1 .
$$

In Sect. 3, TFP is assumed to follow the AR(1) process $\ln \left(\theta_{t+1}\right)=\rho \ln \left(\theta_{t}\right)+\varepsilon_{t+1}^{\theta}, 0 \leq \rho<1$, where $\varepsilon_{t+1}^{\theta}$ is a discrete innovation that equals $\varepsilon_{t+1}^{\theta}=-\sigma_{\theta}$ or $\varepsilon_{t+1}^{\theta}=\sigma_{\theta}$ with probability $1 / 2$, respectively, where $\sigma_{\theta} \geq 0$. $\theta_{t+1}$ thus equals $\theta_{t+1}=\left(\theta_{t}\right)^{\rho} e^{\sigma_{\theta}}$ or $\theta_{t+1}=\left(\theta_{t}\right)^{\rho} e^{-\sigma_{\theta}}$ with probability $1 / 2$. The Euler equation can, thus, be written as:

$$
\begin{gathered}
\pi\left\{\frac{1}{2} H\left(\lambda\left(K_{t+1}\left(\theta_{t}\right)^{\rho} e^{\sigma_{\theta}}\right) e^{\Delta}, K_{t+1}, K_{t},\left(\theta_{t}\right)^{\rho} e^{\sigma_{\theta}}, \theta_{t}\right)+\frac{1}{2} H\left(\lambda\left(K_{t+1},\left(\theta_{t}\right)^{\rho} e^{-\sigma_{\theta}}\right) e^{\Delta}, K_{t+1}, K_{t},\left(\theta_{t}\right)^{\rho} e^{-\sigma_{\theta}}, \theta_{t}\right)\right\} \\
(1-\pi)\left\{\frac{1}{2} H\left(s_{t}^{H} \cdot \lambda\left(K_{t+1},\left(\theta_{t}\right)^{\rho} e^{\sigma_{\theta}}\right) e^{\Delta}, K_{t+1}, K_{t},\left(\theta_{t}\right)^{\rho} e^{\sigma_{\theta}}, \theta_{t}\right)+\frac{1}{2} H\left(s_{t}^{H} \cdot \lambda\left(K_{t+1},\left(\theta_{t}\right)^{\rho} e^{-\sigma_{\theta}}\right) e^{\Delta}, K_{t+1}, K_{t},\left(\theta_{t}\right)^{\rho} e^{-\sigma_{\theta}}, \theta_{t}\right)\right\}=1 .
\end{gathered}
$$

Note that $K_{t+1} \in\left\{K_{t+1}^{L} ; K_{t+1}^{H}\right\}$, where $K_{t+1}^{L}=\lambda\left(K_{t}, \theta_{t}\right) e^{\Delta}$ and $K_{t+1}^{H}=s_{t-1}^{H} K_{t+1}^{L}$.

In the numerical simulations, I define the 'bust' capital stock $\left(K^{L}\right)$ using a second-order (log-quadratic) Taylor expansion of the no-bubble capital decision rule. Let $K_{t+1}=\hat{\lambda}\left(K_{t}, \theta_{t}\right)$ be the second-order Taylor expansion of the no-bubble decision rule $\lambda$. The numerical simulations are thus based on a version of (B.2) in which $\lambda$ is replaced by $\hat{\lambda}$ :

$$
\begin{gathered}
\pi\left\{\frac{1}{2} H\left(\hat{\lambda}\left(K_{t+1},\left(\theta_{t}\right)^{\rho} e^{\sigma_{\theta}}\right) e^{\Delta}, K_{t+1}, K_{t},\left(\theta_{t}\right)^{\rho} e^{\sigma_{\theta}}, \theta_{t}\right)+\frac{1}{2} H\left(\hat{\lambda}\left(K_{t+1},\left(\theta_{t}\right)^{\rho} e^{-\sigma_{\theta}}\right) e^{\Delta}, K_{t+1}, K_{t},\left(\theta_{t}\right)^{\rho} e^{-\sigma_{\theta}}, \theta_{t}\right)\right\} \\
(1-\pi)\left\{\frac{1}{2} H\left(s_{t}^{H} \cdot \hat{\lambda}\left(K_{t+1},\left(\theta_{t}\right)^{\rho} e^{\sigma_{\theta}}\right) e^{\Delta}, K_{t+1}, K_{t},\left(\theta_{t}\right)^{\rho} e^{\sigma_{\theta}}, \theta_{t}\right)+\frac{1}{2} H\left(s_{t}^{H} \cdot \hat{\lambda}\left(K_{t+1},\left(\theta_{t}\right)^{\rho} e^{-\sigma_{\theta}}\right) e^{\Delta}, K_{t+1}, K_{t},\left(\theta_{t}\right)^{\rho} e^{-\sigma_{\theta}}, \theta_{t}\right)\right\}=1 .
\end{gathered}
$$

Conditional on $K_{t}, K_{t+1}, \theta_{t}$, this equation can be used to determine $s_{t}^{H}$. I employ a bisection method for that purpose.

Like the value of the bust probability $\pi$, the specification of the bust capital stock $K^{L}$ is not tied down by economy theory. The only restriction is that the resulting law of motion for capital has to be bounded and strictly positive. I verified that the bubble equilibrium constructed using $\hat{\lambda}$ meets this criterion (it exhibits strictly positive and bounded capital, output and consumption). For model variants with constant TFP, I also computed the no-bubble decision rule $K_{t+1}=\lambda\left(K_{t}, \theta_{t}\right)$ using a shooting algorithm (Judd (1998), ch.10). The second-order accurate approximation and the shooting algorithm give no-bubble decision rules that are very close, even when capital $K_{t}$ is far from steady state. The resulting bubble equilibria too are very similar. Computing the second-order approximation is much faster. 
Table 1. Long-Plosser model (closed economy) with bubbles: business cycle statistics

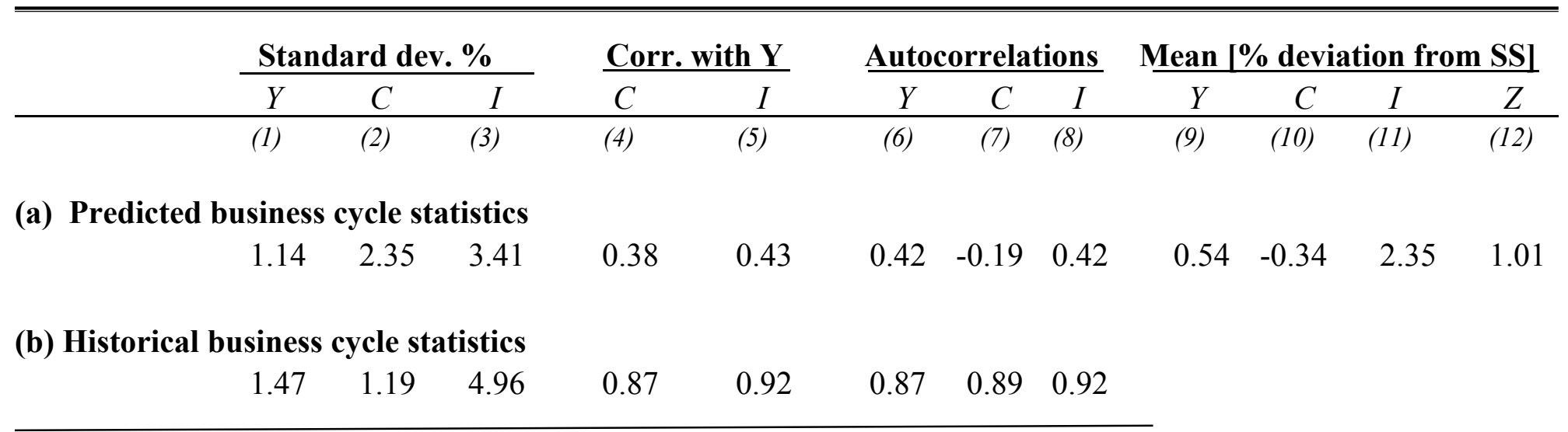

Notes: Row (a) reports simulated business cycle statistics for a Long-Plosser economy with bubbles (no transversality condition); see Sect. 2 of paper. Y: output; $C$ : consumption; I: investment; Z: investment/output ratio.

In the simulated model, fluctuations are just driven by bubble shocks (constant TFP assumed). The bubble process assumes a bust probability $\pi=0.5$.

The model-predicted business cycle statistics are based on one simulation run of $\mathrm{T}=10000$ periods. The reported simulated standard deviations, correlations with output and autocorrelations pertain to medians of statistics across rolling windows of 200 periods. Simulated series were logged and HP filtered (the HP filter was applied separately for each window of 200 periods). 'Means' are sample averages over the total sample of T periods; means are expressed as \% deviations from the deterministic steady state of the no-bubble economy.

Row (b) reports US historical business cycle statistics (quarterly data), 1968q1-2017q4. The empirical data are taken from BEA NIPA (Table 1.1.3). Y: GDP; $C$ : 'Personal consumption expenditures'; I: 'Fixed investment'. 
Table 2. Closed economy RBC model (incomplete capital depreciation): business cycle statistics

Bubble model (no TVC)

\begin{tabular}{|c|c|c|c|c|c|c|c|c|c|c|}
\hline \multicolumn{4}{|c|}{ Bubble shocks; no TFP shocks } & \multicolumn{4}{|c|}{ Bubble \& TFP shocks } & \multirow{2}{*}{\multicolumn{2}{|c|}{$\begin{array}{l}\text { No-bubble model } \\
\text { TFP shocks }\end{array}$}} & \multirow[b]{3}{*}{ Data } \\
\hline \multicolumn{2}{|c|}{ Unit Risk aversion } & \multicolumn{2}{|c|}{ High RA } & \multicolumn{2}{|c|}{ Unit RA } & \multicolumn{2}{|c|}{ High RA } & & & \\
\hline$\pi=0.5$ & $\pi=0.2$ & $\pi=0.5$ & $\pi=0.2$ & $\pi=0.5$ & $\pi=0.2$ & $\pi=0.5$ & $\pi=0.2$ & Unit RA & High RA & \\
\hline (1) & (2) & (3) & (4) & (5) & (6) & (7) & (8) & (9) & (10) & (11) \\
\hline \multicolumn{11}{|c|}{ Standard deviations [in \%] } \\
\hline 0.49 & 1.16 & 0.68 & 1.43 & 1.27 & 1.60 & 0.98 & 1.57 & 1.14 & 0.72 & 1.47 \\
\hline 1.08 & 2.63 & 0.29 & 0.61 & 1.16 & 2.71 & 0.38 & 0.72 & 0.49 & 0.26 & 1.19 \\
\hline 4.29 & 9.38 & 3.22 & 6.51 & 5.38 & 9.85 & 3.86 & 6.72 & 3.33 & 2.20 & 4.96 \\
\hline 0.74 & 1.73 & 1.04 & 2.18 & 0.82 & 1.70 & 1.05 & 2.22 & 0.34 & 0.30 & 1.06 \\
\hline
\end{tabular}

\section{Correlations with GDP}

$\begin{array}{lrrrrrrrrrrr}C & -0.97 & -0.95 & -0.99 & -0.98 & 0.04 & -0.54 & 0.01 & -0.62 & 0.95 & 0.99 & 0.87 \\ I & 0.98 & 0.96 & 0.99 & 0.99 & 0.89 & 0.86 & 0.97 & 0.98 & 0.99 & 0.99 & 0.92 \\ L & 0.99 & 0.97 & 0.99 & 0.99 & 0.79 & 0.81 & 0.45 & 0.82 & 0.98 & -0.96 & 0.82\end{array}$

Autocorrelations

$\begin{array}{llllllllllll}Y & 0.36 & 0.63 & 0.35 & 0.62 & 0.65 & 0.68 & 0.57 & 0.66 & 0.71 & 0.70 & 0.87 \\ C & 0.33 & 0.60 & 0.35 & 0.62 & 0.43 & 0.62 & 0.53 & 0.65 & 0.76 & 0.72 & 0.89 \\ I & 0.36 & 0.63 & 0.37 & 0.64 & 0.53 & 0.65 & 0.51 & 0.65 & 0.70 & 0.70 & 0.92 \\ L & 0.34 & 0.61 & 0.35 & 0.62 & 0.45 & 0.62 & 0.41 & 0.63 & 0.70 & 0.74 & 0.92\end{array}$

Means [\% deviation from no-bubble steady state]

$\begin{array}{lrrrrrrrrrr}Y & 1.41 & 2.80 & 1.25 & 2.12 & 1.37 & 2.75 & 1.31 & 2.17 & 0.00 & 0.00 \\ C & 0.73 & 1.39 & 0.33 & 0.55 & 0.68 & 1.34 & 0.33 & 0.55 & 0.00 & 0.00 \\ I & 3.62 & 7.33 & 4.22 & 7.19 & 3.61 & 7.28 & 4.44 & 7.40 & 0.00 & 0.00 \\ L & 0.36 & 0.74 & -0.02 & -0.02 & 0.34 & 0.73 & 0.01 & -0.03 & 0.00 & 0.00\end{array}$

Mean (capital income - investment)/GDP [in \%]
9.128 .75
8.938 .54
$9.16 \quad 8.78$
$8.92 \quad 8.53$
9.58
9.58
13.42

Fraction of periods with (capital income $>$ investment) [in \%]

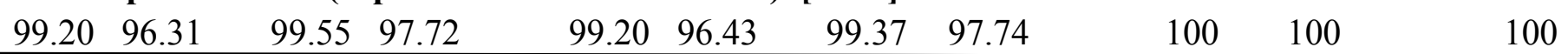

Notes: This Table reports simulated business cycle statistics for a closed economy RBC model with full capital depreciation (see Sect. 3 of paper). Y: output (GDP); $C$ : consumption ; $I$ : investment; $L$ : hours worked.

Cols. (1)-(4) pertain to versions of the bubble model (no transversality condition, TVC) in which fluctuations are just driven by bubble shocks (constant TFP assumed). Cols. (5)-(8) pertain to versions of the bubble model, driven by simultaneous bubble and TFP shocks. Cols. (9)-(10) pertain to versions of the no-bubble model, driven by TFP shocks. 'Unit Risk Aversion': $\log$ utility; 'High Risk Aversion (RA)': consumption utility given by $\ln \left(C_{t}-\bar{C}\right)$, with $\bar{C}>0$. $\pi$ : bust probability of bubble process.

The model-predicted business cycle statistics are based on one simulation run of $\mathrm{T}=10000$ periods (for each model version). Simulated standard deviations, correlations with output and autocorrelations pertain to medians of statistics across rolling windows of 200 periods. Series were logged and HP filtered (HP filter applied separately for each window of 200 periods). 'Means' are sample averages over the total sample of $\mathrm{T}$ periods. The 'Fraction of periods with (capital income $>$ investment)' likewise pertains to the whole simulation run of $\mathrm{T}$ periods.

Col. (11) reports US historical statistics (quarterly data). Statistics for Y,C,I: see Table 1. The empirical measure for ' $L$ ' is: 'Total Employment' (Source: CPS, as reported by FRED database, series CE160V). Historical statistics about 'capital income - investment': based on US annual data 1929-1985 reported by Abel et al. (1989)). 
Table 3. Two-country Dellas model: business cycle statistics

Bubble model (no TVC)

Bubble shocks; Bubble \& No-bubble Model

no TFP shocks TFP shocks TFP shocks

Data

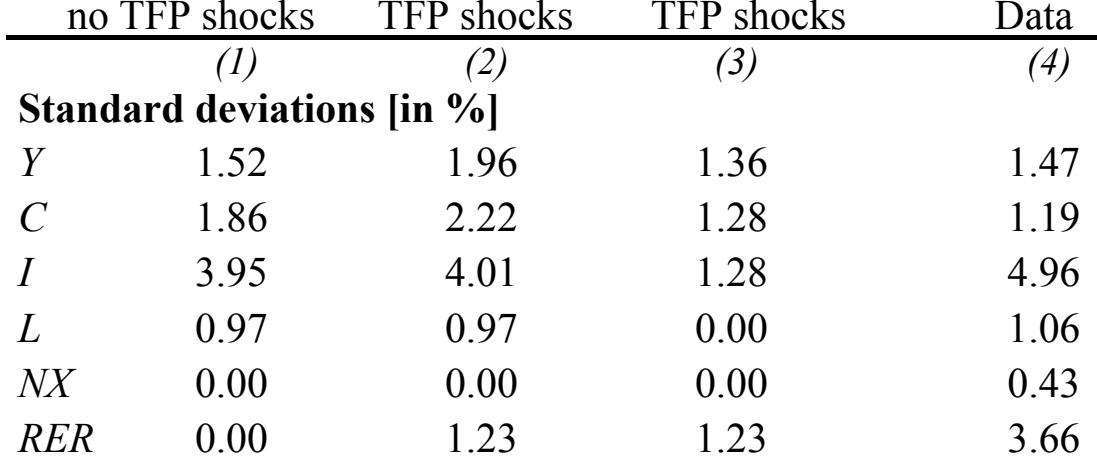

Correlations with domestic GDP

$\begin{array}{lrrrr}C & 0.25 & 0.57 & 0.99 & 0.87 \\ I & 0.76 & 0.88 & 0.99 & 0.92 \\ L & 0.50 & 0.31 & -- & 0.82 \\ N X & -- & -- & --- & -0.51 \\ R E R & -- & -0.41 & -0.54 & -0.27\end{array}$

Autocorrelations

$\begin{array}{lrrrr}Y & 0.63 & 0.77 & 0.80 & 0.87 \\ C & -0.17 & 0.48 & 0.81 & 0.89 \\ I & 0.41 & 0.66 & 0.81 & 0.92 \\ L & 0.10 & 0.10 & -- & 0.92 \\ N X & -- & -- & -- & 0.78 \\ R E R & -- & 0.75 & 0.75 & 0.81\end{array}$

Cross-country correlations

$\begin{array}{lrrrr}Y & 1.00 & 0.68 & 0.39 & 0.53 \\ C & 1.00 & 0.84 & 0.56 & 0.39 \\ I & 1.00 & 0.95 & 0.56 & 0.45 \\ L & 1.00 & 1.00 & -- & 0.39\end{array}$

Means [\% deviation from no-bubble steady state]

$\begin{array}{lrlll}Y & 0.95 & 1.18 & 0.22 & -- \\ C & -0.01 & 0.12 & 0.22 & - \\ I & 3.07 & 3.33 & 0.22 & - \\ L & 0.42 & 0.42 & 0.00 & -\end{array}$

Mean (capital income - investment)/GDP [in \%]
$-0.02$
$-0.02$
0.33
13.42

Fraction of periods with (capital income $>$ investment) [in \%]

$\begin{array}{llll}97.01 & 97.01 & 100.00 & 100.00\end{array}$

Notes: This Table reports simulated business cycle statistics for a two-country RBC world (Dellas) with full capital depreciation (see Sect. 4 of paper). $Y$ : GDP; $C$ : consumption ; $I$ : investment; $L$ : labor input. $N X$ : net exports/GDP; RER: real exchange rate. A rise in RER represents an appreciation. 


\section{Table 3. (continued)}

Col. (1) pertains to a version of the bubble model (no transversality condition, TVC) in which fluctuations are just driven by bubbles shocks (constant TFP assumed). Col. (2) pertains to a version of the bubble model, driven by simultaneous bubble and TFP shocks. The bubble process (Cols. 1 and 2) assumes a bust probability $\pi=0.5$. Col. (3) pertains to a no-bubble model, driven by TFP shocks.

The model-predicted business cycle statistics are based on one simulation run of $\mathrm{T}=10000$ periods (for each model version). Simulated standard deviations, correlations of GDP and autocorrelations pertain to medians of statistics across rolling windows of 200 periods. Series were logged (with exception of NX) and HP filtered (HP filter applied separately for each window of 200 periods). 'Means' are sample averages over the total sample of $\mathrm{T}$ periods. The 'Fraction of periods with (capital income > investment)' likewise pertains to the whole simulation run of $\mathrm{T}$ periods.

Col. (4) reports historical statistics. Historical standard deviations, correlations with domestic GDP and autocorrelations of GDP, consumption, investment, employment, net exports and the real exchange rate as well as the statistics on capital income-investment are based on quarterly US data, 1968q1-2017q4 (see Tables 2 and 3). The empirical measure of $N X$ is: US nominal exports-imports (goods and services) divided by nominal GDP (from BEA NIPA Table 1.1.5). Empirical measure of the US real exchange rate: real effective exchange rate, REER (from BIS; 1968:q1-1993q4: 'narrow index'; 1994q1-2017q4: 'broad index'; a quarterly average of the monthly BIS REER series is used).

Historical cross-country correlations (of $Y, C, I, L$ ) are correlations between US series and series for an aggregate of the Euro Area for 1970q1-2017q4 (logged and HP filtered quarterly series). Source for EA data: ECB Area-wide Model (AWM) database (version Aug. 2018). (EWM series for Y,C,I,L: YER, PCR, ITR, LNN.) 
Bubble model (no TVC)

\begin{tabular}{|c|c|c|}
\hline Bubbles shocks; no TFP shocks & Bubble \& TFP shocks & No-bubble model \\
\hline Unit Risk aversion $\quad$ High RA & $\begin{array}{ll}\text { Unit RA } & \text { High RA }\end{array}$ & TFP shocks \\
\hline
\end{tabular}

$\pi=0.5 \quad \pi=0.2 \quad \pi=0.5 \quad \pi=0.2$

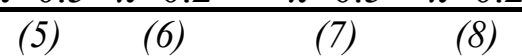

$1.46 \quad 1.78$

$1.18 \quad 1.65$

$1.18 \quad 2.79$

0.41

0.70

$\begin{array}{ll}6.36 & 10.54\end{array}$

4.95

7.34

$\begin{array}{ll}0.88 & 1.79\end{array}$

1.13

2.24

$0.16 \quad 0.16$

0.13

0.13

$\begin{array}{ll}0.32 & 0.32\end{array}$

0.44

0.44

\begin{abstract}
$\begin{array}{ll}0.09 & -0.46\end{array}$
\end{abstract}
$0.03 \quad-0.55$

$0.85 \quad 0.61$

$0.95 \quad 0.96$

$0.94 \quad-0.01$

$0.46 \quad 0.78$

$0.81 \quad 0.81$

$-0.58 \quad-0.46$

$-0.58 \quad-0.68$

$-0.58 \quad-0.39$

$-0.48 \quad-0.68$

1.47

1.19

4.96

1.06

0.43

3.66

C $\quad-0.97-0.95 \quad-0.99 \quad-0.98$

LX

$0.99 \quad 0.97$

-- --

RER

\title{
Autocorrelations
}

$\begin{array}{lll}\text { Y } & 0.36 & 0.63\end{array}$

$\begin{array}{lll}\text { C } & 0.33 & 0.60\end{array}$

$\begin{array}{ll}0.35 & 0.62\end{array}$

$\begin{array}{ll}-0.44 & -0.35\end{array}$

$\begin{array}{ll}0.35 & 0.62\end{array}$

$\begin{array}{ll}0.63 \quad 0.67 \\ 0.46 & 0.62\end{array}$

0.57

0.65

$0.46 \quad 0.62$

0.57

0.65

$0.55 \quad 0.64$

$0.54 \quad 0.64$

0.48

0.64

$0.66 \quad 0.66$

$0.61 \quad 0.61$

0.81

0.81

$0.84 \quad 0.84$

$\begin{array}{rrrr}0.29 & 0.54 & -0.00 & 0.52 \\ 0.96 & 0.99 & 0.98 & 0.99 \\ 0.27 & 0.74 & -0.07 & 0.53 \\ 0.63 & 0.92 & 0.85 & 0.96\end{array}$

0.67

0.75

0.64

0.87

$\begin{array}{ll}0.37 & 0.64 \\ 0.35 & 0.62\end{array}$

0.63

0.71

0.89

L $\quad 0.34 \quad 0.61$

-- --

RER -- --

\section{Cross-country correlations}

$\begin{array}{llll}\mathrm{Y} & 1.00 & 1.00 & 1.00\end{array}$

C $\quad 1.00 \quad 1.00$

$1.00 \quad 1.00$

1.00
1.00
1.00

$1.00 \quad 1.00$

$0.63 \quad 0.92$

$0.85 \quad 0.96$

$0.63 \quad 0.69$

0.92

0.92

$0.61 \quad 0.66$

0.78

$0.84 \quad 0.81$

0.82

L $\quad 1.00 \quad 1.00$

Means [\% deviation from no-bubble steady state]

$\begin{array}{lllllllllll}\mathrm{Y} & 1.41 & 2.80 & 1.25 & 2.12 & 1.65 & 3.02 & 1.45 & 2.29 & 0.00 & 0.00 \\ \mathrm{C} & 0.73 & 1.39 & 0.33 & 0.55 & 0.95 & 1.60 & 0.44 & 0.65 & 0.00 & 0.00 \\ \mathrm{I} & 3.62 & 7.33 & 4.22 & 7.19 & 3.93 & 7.61 & 4.72 & 7.61 & 0.00 & 0.00 \\ \mathrm{~L} & 0.36 & 0.74 & -0.02 & -0.02 & 0.35 & 0.73 & 0.09 & 0.05 & 0.00 & 0.00\end{array}$

Mean (capital income - investment)/GDP [in \%]
$9.12 \quad 8.75$
$8.93 \quad 8.54$
9.158 .78
8.89
8.51
9.559 .58
13.42

Fraction of periods with (capital income $>$ investment) [in \%]
$99.20 \quad 96.31$
$99.55 \quad 97.72$
$99.20 \quad 96.45$
$99.44 \quad 97.75$
$100 \quad 100$
100

Notes: This Table reports simulated business cycle statistics for a two-country RBC model with incomplete capital depreciation (see Sect. 5 of paper). Y: GDP; $C$ : consumption ; $I$ : investment; $L$ : labor input; $N X$ : net exports/GDP; RER: real exchange rate. A rise in $\mathrm{R} E R$ represents an appreciation. 


\section{Table 4. (continued)}

Cols. (1)-(4) pertain to versions of the bubble model (no transversality condition, TVC) in which fluctuations are just driven by bubbles (constant TFP assumed). Cols. (5)-(8) pertain to versions of the bubble model, driven by simultaneous bubble and TFP shocks. Cols. (9)-(10) pertain to versions of the no-bubble model, driven by TFP shocks.

'Unit Risk Aversion': log utility; 'High Risk Aversion (RA)': consumption utility given by $\ln \left(C_{t}-\bar{C}\right)$, with $\bar{C}>0$.

$\pi$ : bust probability of bubble process.

The model-predicted business cycle statistics are based on one simulation run of $\mathrm{T}=10000$ periods (for each model version). Simulated standard deviations, correlations of GDP and autocorrelations pertain to medians of statistics across rolling windows of 200 periods. Series that were logged (with exception of NX) and HP filtered (HP filter applied separately for each window of 200 periods). 'Means' are sample averages over the total sample of T periods. The 'Fraction of periods with (capital income > investment)' likewise pertains to the whole simulation run of $\mathrm{T}$ periods.

Col. (11) reports historical statistics (see Table 3). 


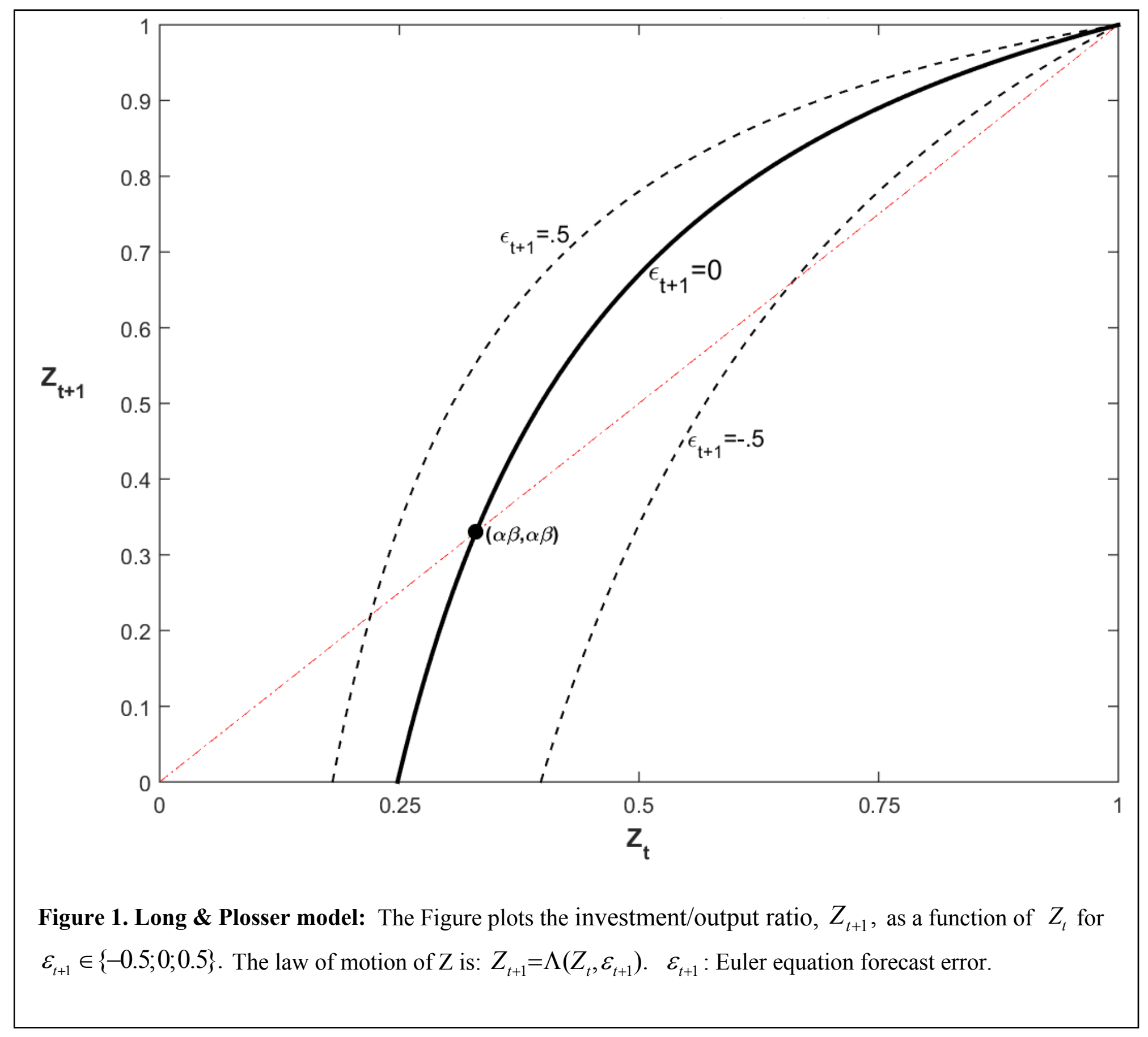




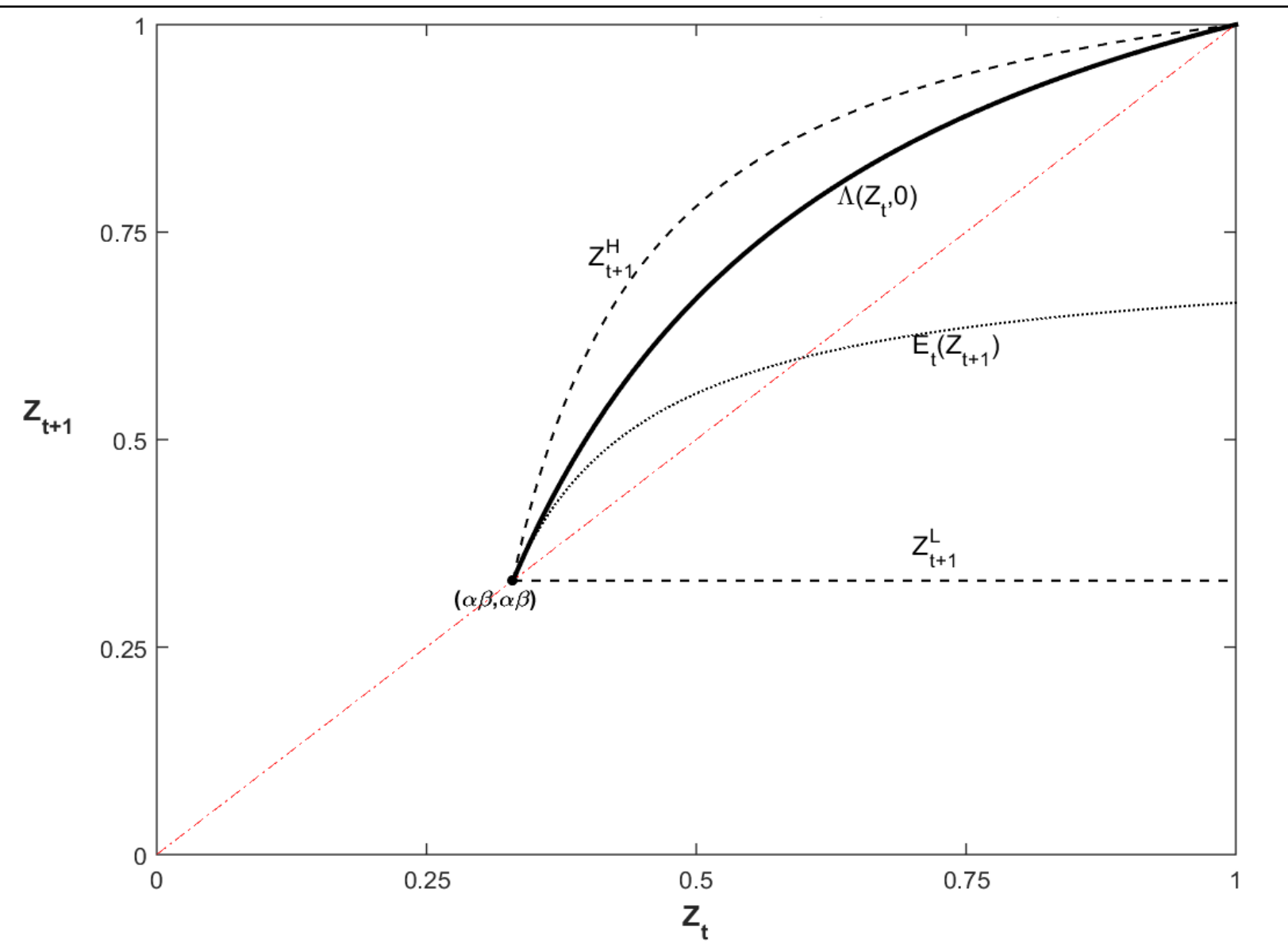

(1) 'Boom' and 'Bust' values of date $t+1$ investment/output ratio $\left(Z_{t+1}^{H}, Z_{t+1}^{L}\right)$ and expected value $\left(E_{t} Z_{t+1}\right)$, shown as functions of $Z_{t} \in[\alpha \beta+\Delta, 1) . \Lambda\left(Z_{t}, 0\right)$ is value of $Z_{t+1}$ in a deterministic economy (zero Euler equation forecast error).

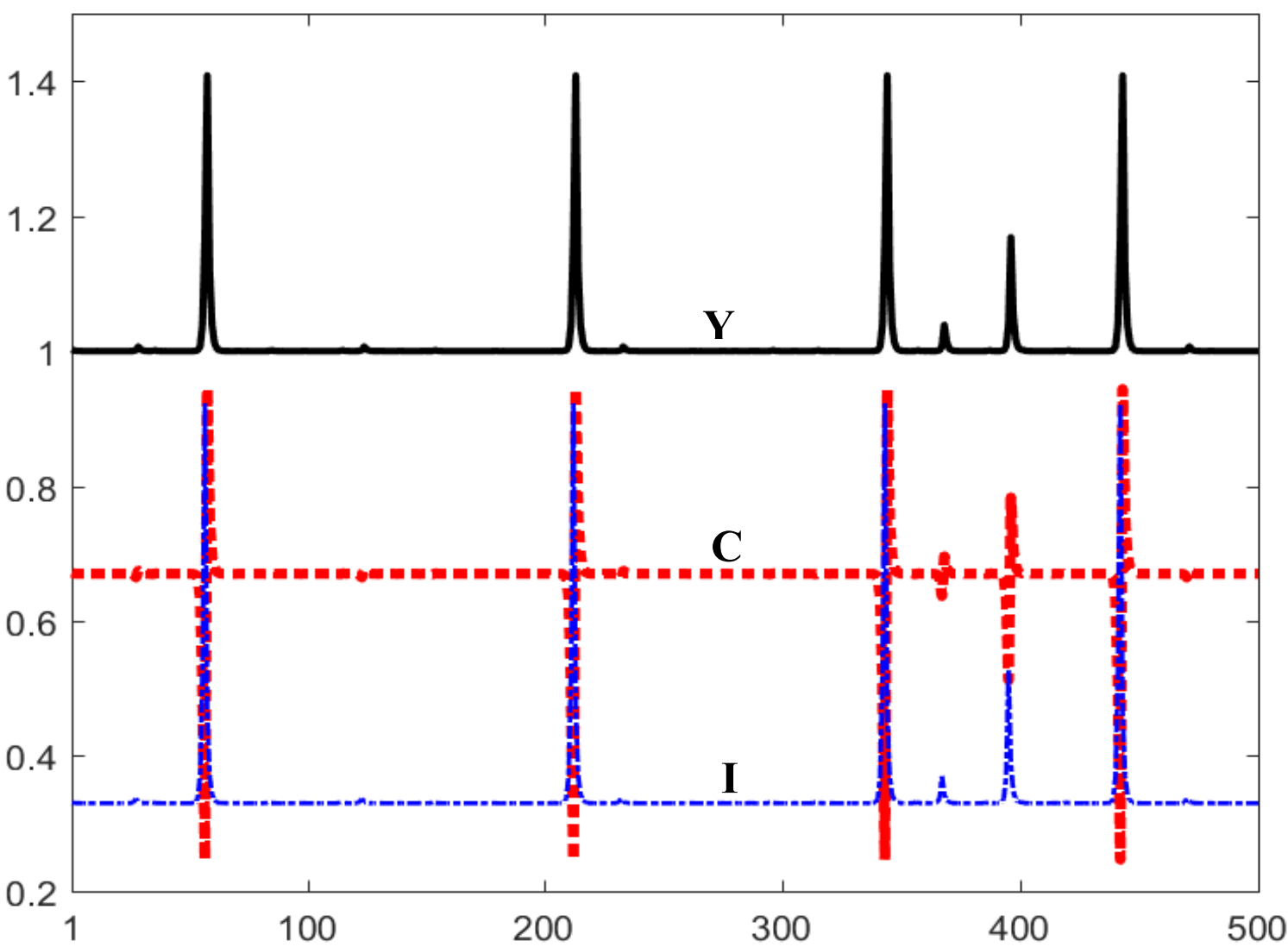

(2) Simulated paths

Figure 2. Long \& Plosser economy with bubbles (no transversality condition)

Simulated series of output (Y, continuous black line), consumption (C, red dashed line) and investment (I, blue dashdotted line) are normalized by steady state output. $-Y-=-\mathrm{C}-\cdot--\mathrm{I}^{\prime}$ 


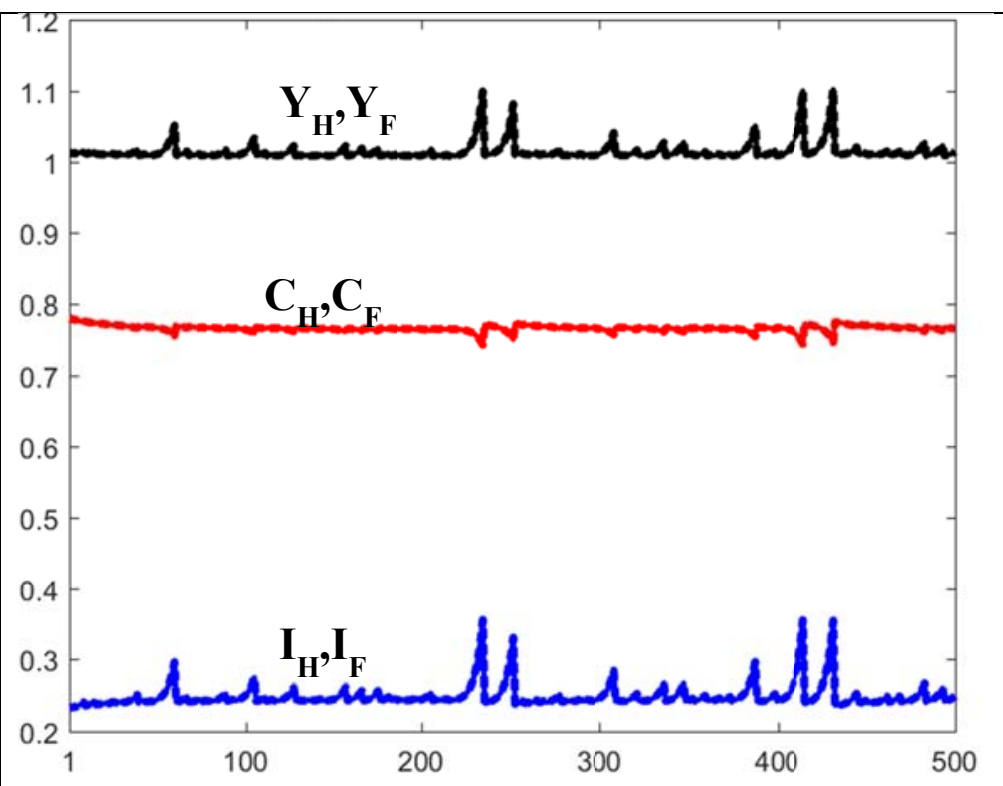

(1) Just bubble shocks (constant TFP)

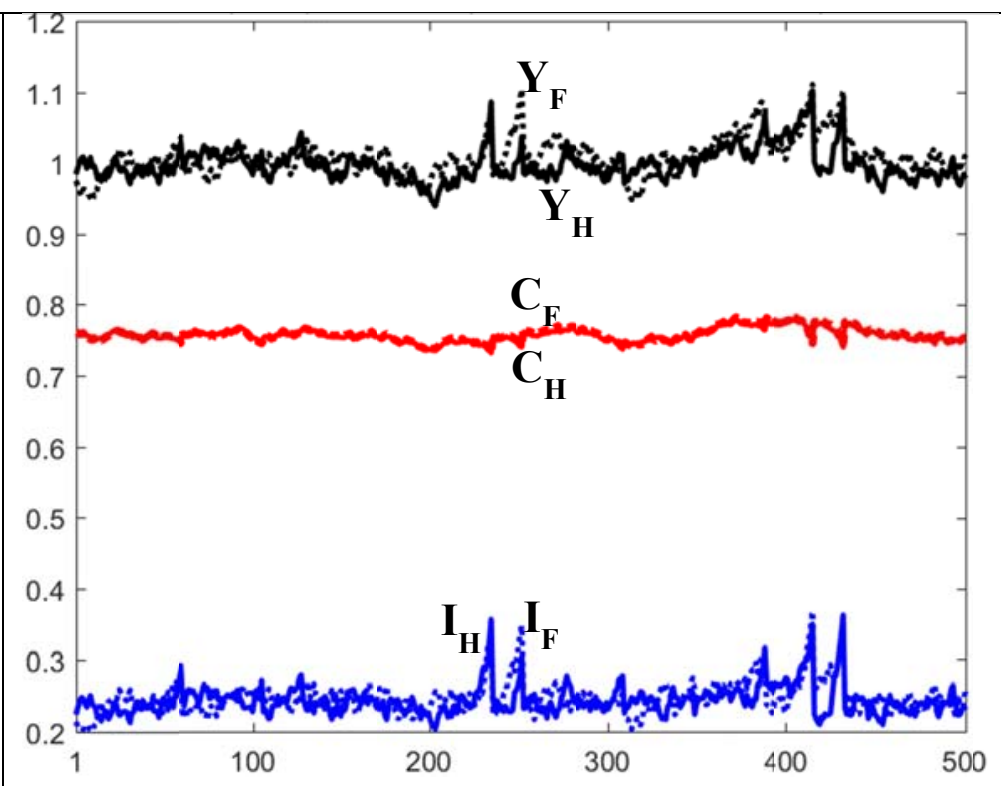

(2) Bubble \& TFP shocks

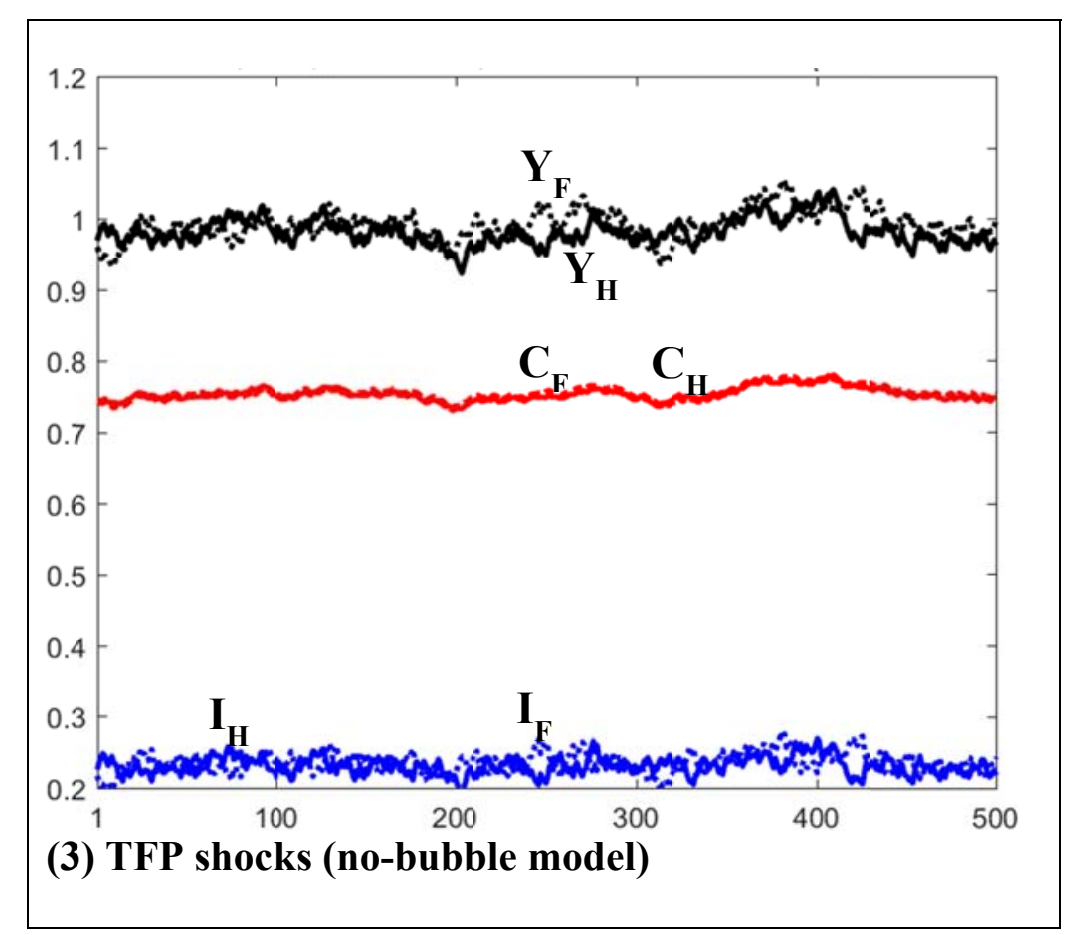

Figure 4. Two-country RBC model (incomplete capital depreciation): simulated paths

This Figure assumes the two-country RBC model with incomplete capital depreciation, 'High risk aversion' and a bust probability $\pi=0.20$ (see Sect. 5). Simulated paths of Home and Foreign GDP ( $\mathrm{Y}_{\mathrm{H}}, \mathrm{Y}_{\mathrm{F}}$ : continuous and dotted black lines), Home and Foreign consumption $\left(\mathrm{C}_{\mathrm{H}}, \mathrm{C}_{\mathrm{F}}\right.$ : continuous and dotted red lines) and investment $\left(\mathrm{I}_{\mathrm{H}}, \mathrm{I}_{\mathrm{F}}\right.$ : continuous and dotted blue lines) are shown. The plotted series are normalized by steady state GDP. - $Y_{H} \cdot \cdots \cdot \cdot Y_{F}-C_{H} \cdot \cdot \cdot \cdot \cdot C_{F}-I_{H} \cdot \cdot \cdot \cdot I_{F}$

Panel (1) pertains to a bubble model (no transversality condition), in which fluctuations are just driven by bubble shocks (constant TFP assumed). Panel (2) pertains to a bubble model, driven by joint bubble and TFP shocks. Panel (3) pertains to a no-bubble model, driven by TFP shocks. 